\title{
Reações adversas relacionadas a medicamentos frente ao uso da quimioterapia combinada e/ou alternativa utilizados para tratar casos de hanseníase: uma revisão integrativa
}

\author{
Adverse drug reactions in the use of combination and/or alternative chemotherapy used to treat \\ leprosy cases: an integrative review \\ Reacciones adversas relacionadas con medicamentos ante el uso de quimioterapia combinada y/o \\ alternativa utilizados para tratar casos de lepra: una revisión integradora
}

A hanseníase é uma doença infectocontagiosa de caráter crônico, causada pelo Mycobacterium leprae. O tratamento da hanseníase é a poliquimioterapia - PQT, uma associação de Rifampicina, Dapsona e Clofazimina que pode causar vários efeitos adversos. Este trabalho tem como objetivo analisar as produções científicas acerca dos aspectos 
associados aos efeitos colaterais, reações adversas e/ou sinais e sintomas relacionados a medicamentos frente ao uso da quimioterapia combinada e/ou alternativa utilizados para tratar a hanseníase. Trata-se de uma revisão integrativa para a qual as bases de dados PubMed, LILACS, CINAHL e Google Acadêmico foram selecionadas para a busca de estudos primários, publicados entre 1991 e 2020, nos idiomas português, inglês e espanhol. Foram identificados 4.724 estudos, sendo 50 artigos elegíveis, dos quais 33 compuseram a amostra final. Os principais temas exibidos pelos artigos foram: PQT disponível para tratar a hanseníase e suas complicações; implicações e efeitos adversos causados pelos medicamentos; condutas para amenizar esses efeitos; capacitação aos profissionais da saúde sobre os efeitos do tratamento; relevância do paciente ser informado sobre o tratamento e seus efeitos adversos; importância de diagnosticar e tratar a SHD rapidamente; monitoramento dos exames laboratoriais; medidas preventivas para tratar possíveis complicações; notificação dos efeitos adversos e a escassez de estudos multicêntricos que avaliem efeitos adversos e eficácia do tratamento. É necessário capacitação e educação permanente das equipes gestoras e multiprofissionais da saúde para que as ações repercutam de forma positiva na qualidade da assistência prestada favorecendo dessa maneira à implementação de mecanismos de vigilância e controle das reações adversas.

Palavras-chave: Hanseníase; Reações adversas; Poliquimioterapia.

\begin{abstract}
Leprosy is a chronic infectious disease caused by Mycobacterium leprae. The treatment of leprosy is the multidrug therapy - MDT, an association of Rifampicin, Dapsone, and Clofazimine that can cause several adverse events. This paper aims to analyze the scientific productions about aspects related to side effects, adverse reactions, and/or signs and symptoms concerning medications in the use of combination and/or alternative chemotherapy used to treat leprosy. This is an integrative review for which the PubMed, LILACS, CINAHL, and Google Scholar databases were selected to search for primary studies, published between 1991 and 2020, in Portuguese, English, and Spanish. A total of 4.724 studies were identified, with 50 eligible papers, of which 33 comprised the final sample. The main themes presented by the papers were: MDT available to treat leprosy and its complications; implications and adverse effects caused by medications; actions to mitigate these effects; training for the health personnel on the treatment effects; relevance of warning the patient about the treatment and its adverse effects; the importance of quickly diagnosing and treating DHS; monitoring of laboratory tests; preventive measures to treat potential complications; notification of adverse effects and scarcity of multicentric studies that assess adverse effects and efficacy of treatment. The permanent training and education of the management and multidisciplinary health teams are necessary so that the actions have a positive impact on the quality of care provided, thus benefiting the implementation of mechanisms for surveillance and control of adverse reactions.
\end{abstract}

Keywords: Leprosy; Adverse reactions; Multidrug therapy.

\title{
Resumen
}

La lepra es una enfermedad infecciosa crónica causada por Mycobacterium leprae. El tratamiento de la lepra es la quimioterapia combinada, una asociación de Rifampicina, Dapsona y Clofazimina que puede causar varios efectos secundarios. Este trabajo tiene como objetivo analizar las producciones científicas sobre aspectos relacionados con los efectos secundarios, las reacciones adversas y/o los signos y síntomas con respecto a los medicamentos ante el uso de quimioterapia combinada y/o alternativa para el tratamiento de la lepra. Se trata de una revisión integradora para la que se seleccionaron las bases de datos PubMed, LILACS, CINAHL y Google Scholar para la búsqueda de estudios primarios, publicados entre 1991 y 2020 , en portugués, en inglés y en español. Se identificaron un total de 4.724 estudios, con 50 artículos elegibles, de los cuales 33 compusieron la muestra final. Los principales temas presentados por los artículos fueron: quimioterapia combinada disponible para tratar la lepra y sus complicaciones; implicaciones y efectos secundarios causados por medicamentos; acciones para mitigar estos efectos; capacitación para los personales de salud sobre los efectos del tratamiento; relevancia de que se informe al paciente sobre el tratamiento y sobre sus efectos secundarios; importancia de diagnosticar y de tratar rápidamente las SHD; monitoreo de pruebas de laboratorio; medidas preventivas para tratar posibles complicaciones; notificación de efectos secundarios y escasez de estudios multicéntricos que evalúen los efectos secundarios y la eficacia del tratamiento. Son necesarias formación y educación permanente de los equipos directivos y multidisciplinarios de salud para que las acciones tengan un impacto positivo en la calidad de la atención prestada, favoreciendo, por lo tanto, la implementación de mecanismos de vigilancia y de control de reacciones adversas.

Palabras clave: Lepra; Reacciones adversas; Quimioterapia combinada.

\section{Introdução}

A hanseníase é uma doença infectocontagiosa de caráter crônico, causada pelo Mycobacterium leprae. Seu contágio está fortemente relacionado com o convívio próximo e prolongado junto a portador bacilífero sem tratamento, ou com tratamento irregular. As principais manifestações clínicas envolvem acometimento do sistema nervoso periférico, seguido de lesões de pele, e o acometimento de órgãos (Margarido \& Rivitti, 2015; Brasil, 2017). 
No ano de 2019, foram diagnosticados 27.864 casos novos de hanseníase. A taxa de detecção geral de casos novos da doença no Brasil foi de 13,23 casos para cada 100 mil habitantes. A hanseníase está presente em todos os estados brasileiros, o que mantém o país em um parâmetro de alta endemicidade, porém há uma concentração da doença nas regiões mais ao centro e norte do país (Brasil, 2020).

O tratamento específico da hanseníase, recomendado pela Organização Mundial de Saúde - OMS e preconizado pelo Ministério da Saúde do Brasil é a poliquimioterapia - PQT, uma associação de Rifampicina (RPM), Dapsona (DDS) e Clofazimina (CFZ), porém os pacientes podem ser tratados com uma combinação alternativa ROM (Rifampicina, Ofoxacino e Minociclina) por algum contratempo causado pelos medicamentos comumente utilizados (Brasil, 2017; Fiqueiredo \& Heinen, 2017).

Os medicamentos utilizados na PQT podem causar vários efeitos adversos (Brasil, 2017), tais como erupções na pele, anemia hemolítica, icterícia, meta-hemoglobinemia, agranulocitose, supressão da medula óssea, insuficiência renal, neuropatia periférica, pancitopenia (Guragain, Upadhayay \& Bhattarai, 2017) até a síndrome de hipersensibilidade à dapsona (SHD), uma reação adversa rara, porém grave, envolvendo múltiplos órgãos e que pode causar óbito (Wang, Parimi, Liu \& Zhang, 2017).

Diferentes estudos têm relatado vários efeitos adversos causados pela PQT, como a anemia hemolítica, metemoglobinemia, distúrbios gastrointestinais, reação cutânea, anormalidades hepáticas, dor de cabeça, tontura, síndrome da dapsona, síndrome semelhante à gripe, hematêmese, febre, dermatite esfoliativa, prurido, erupção papular eritematosa, leucopenia, distúrbios psiquiátricos, fraqueza muscular e edemas de membros inferiores (Soucre, Martínez, Crespo, Guevara \& Oliver, 2018; Singh, Azad \& Kaur, 2011; Deps et al., 2007; Pandey, Shrestha, Lewis, Hawksworth \& Walker, 2007).

Soucre et al. (2018), mostraram que dentre os 121 pacientes avaliados, 29,0\% apresentaram reações adversas a PQT, sendo que $100 \%$ destas foram relacionadas a dapsona. Singh et al. (2011) descreveram em seu trabalho que dos 176 pacientes, 45\% (79) apresentaram efeitos adversos a pelo menos um componente da PQT - 73 pacientes (41\%) devido à dapsona, oito (5\%) devido à rifampicina e $16(24 \%)$ devido à clofazimina. No trabalho de Pandey et al. (2007), 2\% dos pacientes desenvolveram a (SHD) e 0,25\% morreram devido a esta síndrome.

Compreender os principais efeitos adversos frente a PQT para tratamento da hanseníase é fundamental para o delineamento de açães de prevenção, identificação e manejo adequado dessa condição, com vistas a minimizar os efeitos evitáveis. Assim, objetivou-se analisar as produções científicas acerca dos aspectos associados aos efeitos colaterais, reações adversas e/ou sinais e sintomas relacionados a medicamentos frente ao uso da quimioterapia combinada e/ou alternativa utilizados para tratar os casos de hanseníase.

\section{Metodologia}

Trata-se de uma Revisão Integrativa da Literatura, seguindo o fluxograma do Preferred Reporting Items for Systematic Reviews and Meta-Analyses (PRISMA) (Liberati et al., 2009). Para tanto, seguiram-se os seis passos para a elaboração da revisão integrativa: 1) Elaboração da pergunta norteadora; 2) Busca na literatura; 3) Coleta de dados; 4) Análise crítica dos estudos incluídos; 5) Discussão dos resultados; e 6) Apresentação da revisão integrativa (Whittemore \& Knafl, 2005).

A formulação da pergunta considerou o acrônimo PICO, sendo P (População, ou o paciente, ou o problema abordado (Population/Patient/Problem), I (fenômeno de Interesse - Interest), C (Contexto ou Comparação - Context) e o O (Desfecho Outcomes) que se baseia na construção de questões de pesquisa de natureza diversa, possibilitando a formulação de uma pergunta de pesquisa que tenha validade e aplicabilidade, baseada em evidências, para resolução de questões clínicas atuais (Santos, Pimenta \& Nobre, 2007). 
Para guiar este estudo, elegeu-se a seguinte questão norteadora: Ser humano acometido por hanseníase (P) em uso da quimioterapia combinada e/ou alternativa (I) apresentam quais efeitos colaterais, reações adversas e/ou sinais e sintomas relacionados ao tratamento $(\mathrm{O})$ descritos na literatura científica?

Um protocolo de pesquisa foi elaborado, no qual foram estabelecidos os critérios de inclusão e exclusão. Os critérios de inclusão foram: artigos publicados entre os anos de 1991 a 2020; artigo em português, inglês e espanhol completos e gratuitos; estudos primários. Foram excluídos: estudos secundários (protocolo de revisões e revisões); Tese, Dissertação, Trabalho de Conclusão de Curso, Monografia; Carta Editorial, Resenhas, Revisão de livros, Erratas e comentários de artigos, Obituários; Duplicidade; não atende a pergunta da pesquisa; não encontrado/site.

A busca dos artigos foi realizada por meio do sistema da Biblioteca Central da Universidade de Brasília e do Portal de periódicos CAPES entre outubro a dezembro de 2020 nas seguintes bases de dados: Literatura Latino-Americana e do Caribe em Ciências da Saúde (LILACS), National Library of Medicine National Institutes of Health (PubMed) Cumulative Index to Nursing via Medical Literature Analysis and Retrieval Sistem (MEDLINE), Allied Health Literature (CINAHL) e Google Acadêmico. Adicionalmente, foram selecionados estudos por busca manual por meio da verificação da lista de referências dos arquivos inclusos.

Utilizou-se os descritores : "hanseniase”, "lepra”, "doença de Hansen”, “quimioterapia combinada”, "quimioterapia de combinação","poliquimioterapia", "efeitos colaterais e reações adversas relacionados a medicamentos", "efeitos colaterais e reações adversas", "efeitos adversos", "reações adversas relacionados a medicamentos", "sinais e sintomas", "tratamento farmacológico", "dapsona", "rifampicina", "clofazimina", "minoclina", "ofloxacino", "leprosy", "drug administration schedule", "drug-related side effects and adverse reactions", "adverse drug reactions", "drug therapy, combination", "lepra", "quimioterapia combinacion", "quimioterapia combinada", "efectos colaterales y reacciones adversas relacionados con medicamentos", "farmacoterapia de combinación", "Mycobacteriun leprae", "signos y síntomas" disponíveis no Medical Subject Headings (MeSH) e no Descritores em Ciências da Saúde (DeCS), nos idiomas português, inglês e espanhol. A estratégia de busca seguiu os critérios de cada base de dados combinados com o operador boleano AND e, agrupados e combinados de forma a esgotar todas as possibilidades e prover que um maior número possível de referências fosse encontrado.

Foi recuperado um total de 4.724 artigos, nos quais se aplicaram três etapas de identificação e seleção: na primeira etapa, foi iniciada a identificação dos artigos nas bases de dados; na segunda etapa, a seleção dos artigos por meio da leitura dos títulos e resumos; e, na terceira etapa, a elegibilidade dos artigos de acordo com a pergunta de pesquisa.

Para a seleção dos artigos, quatro duplas de pesquisadores independentes avaliaram os estudos previamente identificados. Nos casos em que um consenso não foi obtido, um terceiro examinador foi convidado a participar em situações de divergências em relação à inclusão do artigo para compor a fase subsequente.

Todos os títulos e resumos inicialmente selecionados foram exportados de cada base de dados para o programa Endnote versão 9 (Thomson, Reuters, Carlsbad, USA) para análise, gerenciamento e transformação das referências para o formato BiBTeX. Posteriormente, ainda nesta esta etapa, usou-se o Software State of the Artthrough Systematic Review (StArt®) desenvolvido pelo Laboratório de Pesquisa de Engenharia de Software do Departamento de Computação da Universidade Federal de São Carlos (Fabbri et al., 2016) para o gerenciamento das etapas da revisão.

Com o intuito de sintetizar as informações dos artigos, os dados extraídos dos estudos foram compilados de forma descritiva em uma tabela (1) e um quadro (1). 


\section{Resultados}

Foram identificados 4.724 estudos pelas buscas nas bases de dados sendo que 33 compuseram a amostra final. O processo de seleção dos estudos está apresentado na Figura 1.

Figura 1- Fluxograma do processo de identificação e seleção de artigos.

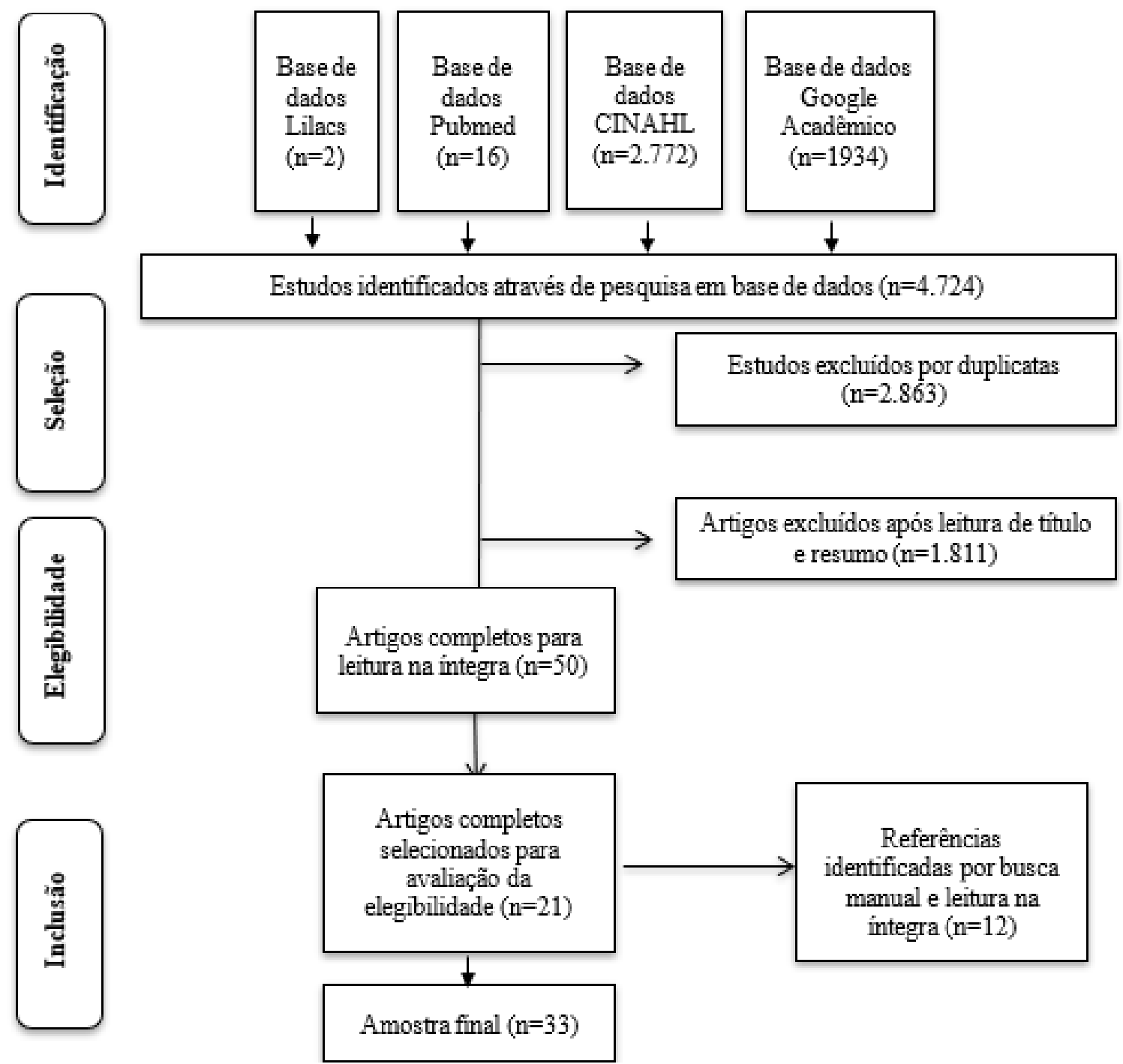

Fonte: Adaptado do diagrama PRISMA-P 2009 Statement (Moher, Tetzlaff \& Altman, 2009).

Dos 33 artigos elegíveis houve publicação em diversos periódicos, porém as maiores taxas foram nas revistas Leprosy Review e Hansenologia Internationalis (15,1\%). Ao avaliar o ano de publicação pode-se observar que as publicações ocorreram a partir de 1992, tendo destaque para o ano 2018 com cinco (05) artigos publicados.

No período estudado, o Brasil foi o país que mais teve publicação sobre o tema tratado nesta pesquisa $(45,5 \%)$.

Dentre os trabalhos revisados, 17 (51,5\%) relatam a ocorrência de reações adversas relacionadas à dapsona, sendo que em $04(12,1 \%)$ foi relatado a ocorrência de óbito. Com intuito de melhor apresentação, os trabalhos que atenderam os critérios de inclusão e exclusão foram organizados em uma tabela (Tabela 1) e um quadro (Quadro 1) de forma codificada por sequência alfanumérica, iniciado pela letra "E" (primeira letra da palavra "estudo") acompanhada por um número arábico em intervalo de 1 a 33. A ordem escolhida foi ano de publicação. 
Na Tabela 1, encontram-se sumarizadas as características de cada estudo. A sistematização dos resultados encontra-se no Quadro 1. Desses resultados, surgiram cinco temáticas: droga utilizada, eventos clínicos, eventos laboratoriais/imagem, condutas adotadas e contribuições esperadas/sugestões nas condutas.

Tabela 1. Identificação das publicações quanto aos autores, periódico, ano, qualis, objetivo, tipo, local, população e amostra do estudo.

\begin{tabular}{|c|c|c|c|}
\hline $\mathbf{N}^{\mathbf{o}}$ & Autores/Periódico/Ano/Qualis & Objetivo & $\begin{array}{l}\text { Tipo e } \quad \text { Local do } \\
\text { estudo/População/Amostra }\end{array}$ \\
\hline E1 & $\begin{array}{l}\text { AUGUSTO FILHO, T. et al. } \\
\text { Educação Ciência e Saúde/2020/C }\end{array}$ & $\begin{array}{l}\text { Verificar os efeitos adversos às drogas usadas e } \\
\text { irregularidades no tratamento da hanseníase e a } \\
\text { ocorrência na mudança de esquema terapêutico, a } \\
\text { partir da revisão dos prontuários de pacientes } \\
\text { tratados nas Unidades Básicas de Saúde do } \\
\text { município de Cajazeiras-PB }\end{array}$ & $\begin{array}{l}\text { Estudo retrospectivo } \\
\text { documental/ } \\
\text { Cajazeiras-PB } \\
48 \text { sujeitos. }\end{array}$ \\
\hline E2 & $\begin{array}{l}\text { FAUST, L. et al. Journal of } \\
\text { Cutaneous Medicine and } \\
\text { Surgery/2020/B2 }\end{array}$ & $\begin{array}{l}\text { Avaliar o resultado do uso da ofloxacina no } \\
\text { tratamento da hanseníase. }\end{array}$ & $\begin{array}{l}\text { Retrospectivo e descritivo } \\
\text { Não descrito no artigo } \\
26 \text { pacientes }\end{array}$ \\
\hline E3 & $\begin{array}{l}\text { SEREA, R.V.P.et al. Brazilian } \\
\text { Journal of Development/ 2020/ B2 }\end{array}$ & Descrever um caso de síndrome a sulfona. & $\begin{array}{l}\text { Relato de Caso } \\
\text { Não descrito no artigo. } \\
\text { Homem de } 26 \text { anos. }\end{array}$ \\
\hline E4 & $\begin{array}{l}\text { CRAIG, J. et al. American Journal } \\
\text { of Tropical Medicine and } \\
\text { Hygiene/2019/A2 }\end{array}$ & $\begin{array}{l}\text { Apresentar um caso de reação intercorrente tipo } 1 \text { e } \\
\text { SHD em um paciente com hanseníase multibacilar } \\
\text { recentemente iniciado em tratamento multidroga. }\end{array}$ & $\begin{array}{l}\text { Relato de caso/ } \\
\text { Canadá } \\
\text { Homem de } 47 \text { anos. }\end{array}$ \\
\hline E5 & $\begin{array}{l}\text { MERANTHI. F. et al. Case Reports } \\
\text { in Medicine/2019/B4 }\end{array}$ & $\begin{array}{l}\text { Descrever o caso de agranulocitose induzida por } \\
\text { dapsona. }\end{array}$ & $\begin{array}{l}\text { Relato de caso } \\
\text { Sri Lanka } \\
\text { Menina de } 7 \text { anos. }\end{array}$ \\
\hline E6 & $\begin{array}{l}\text { SHARMA, B. International } \\
\text { Healthcare } \\
\text { Journal/2018/Não indexada }\end{array}$ & $\begin{array}{l}\text { Relatar o caso de um jovem que desenvolveu a } \\
\text { SHD após o uso da droga. }\end{array}$ & $\begin{array}{l}\text { Relato de caso/ } \\
\text { Não descrito no artigo } \\
\text { Homem de } 25 \text { anos. }\end{array}$ \\
\hline E7 & $\begin{array}{l}\text { NAIR. S. P. et al. Indian } \\
\text { Dermatology Online Journal/ 2018/ } \\
\text { não encontrado }\end{array}$ & $\begin{array}{l}\text { Descrever a prevalência de reações adversas a } \\
\text { medicamentos da PQT. }\end{array}$ & $\begin{array}{l}\text { Retrospectivo e descritivo } \\
\text { Brasil } \\
901 / 28\end{array}$ \\
\hline E8 & $\begin{array}{l}\text { CASTRO PANTE, C. et al. Leprosy } \\
\text { review/ 2019/B1 }\end{array}$ & $\begin{array}{l}\text { Determinar as principais reações adversas graves à } \\
\text { multiterapia (MDT), bem como como as } \\
\text { características dos pacientes. }\end{array}$ & $\begin{array}{l}\text { Estudo observacional, } \\
\text { retrospectivo e descritivo } \\
\text { São Paulo-SP } \\
158 / 22\end{array}$ \\
\hline E9 & $\begin{array}{l}\text { SILVA, R.C. et al. Revista Médica } \\
\text { de Minas Gerais/ 2018/B3 }\end{array}$ & $\begin{array}{l}\text { Apresentar um caso de paciente em tratamento com } \\
\text { poliquimioterapia que desenvolveu insuficiência } \\
\text { renal aguda. }\end{array}$ & $\begin{array}{l}\text { Relato de Caso } \\
\text { Brasil - MG } \\
\text { Mulher de } 51 \text { anos. }\end{array}$ \\
\hline E10 & $\begin{array}{l}\text { SOUCRE, N. et al. Dermatologia } \\
\text { Venezuelana/ 2018/ não encontrado }\end{array}$ & $\begin{array}{l}\text { Determinar as reações adversas a poliquimioterapia } \\
\text { para enfermidade de Hanseníase na consulta de } \\
\text { dermatología do Instituto de Biomedicina, no } \\
\text { período entre agosto } 2014 \text { e agosto } 2015 \text {. }\end{array}$ & $\begin{array}{l}\text { Retrospectivo e descritivo } \\
\text { Caracas - Venezuela } \\
121 / 29\end{array}$ \\
\hline E11 & GONÇALVES, T.S.,et al./ Revista & Relatar a síndrome da sulfona em paciente com & Relato de Caso \\
\hline
\end{tabular}




\begin{tabular}{|c|c|c|c|}
\hline & de Patologia do Tocantins/ 2018/ B4 & hanseníase. & $\begin{array}{l}\text { To- Brasil } \\
\text { Mulher de } 46 \text { anos. }\end{array}$ \\
\hline E12 & $\begin{array}{l}\text { GURAGAIN, S. et al. Clinical } \\
\text { Pharmacology: Advances and } \\
\text { Application/ 2017/ não encontrado }\end{array}$ & $\begin{array}{l}\text { Investigar a ocorrência e as características clínicas } \\
\text { de reações adversas a medicamentos (RAMs) } \\
\text { relacionadas à dapsona entre pacientes com } \\
\text { hanseníase submetidos à poliquimioterapia (PQT) } \\
\text { de } 2010 \text { a } 2013 \text { na região oeste do Nepal }\end{array}$ & $\begin{array}{l}\text { Estudo retrospectivo } \\
\text { Nepal } \\
18 \text { sujeitos }\end{array}$ \\
\hline E13 & $\begin{array}{l}\text { KESARI, H.V., et al. Journal of } \\
\text { Clinical and Diagnostic Research/ } \\
\text { 2017/ B2 }\end{array}$ & $\begin{array}{l}\text { Descrever o caso de uma mulher com síndrome de } \\
\text { hipersensibilidade a dapsona. }\end{array}$ & $\begin{array}{l}\text { Relato de caso } \\
\text { Não descrito no artigo } \\
\text { Mulher de } 30 \text { anos. }\end{array}$ \\
\hline E14 & $\begin{array}{l}\text { GAVILANES, M.C. et. al. Leprosy } \\
\text { review/2015/B1 }\end{array}$ & $\begin{array}{l}\text { Descrever um caso de síndrome hipersensibilidade } \\
\text { à dapsona. }\end{array}$ & $\begin{array}{l}\text { Relato de caso } \\
\text { Rio de Janeiro - RJ } \\
\text { Homem de } 31 \text { anos. }\end{array}$ \\
\hline E15 & $\begin{array}{lr}\text { KUBOTA R.M.M., et al. } \\
\text { Hansenologia } & \text { Internationalis/ } \\
\text { 2014/B4 } & \end{array}$ & $\begin{array}{l}\text { Determinar as causas da mudança do esquema } \\
\text { terapêutico e avaliar as condições clínicas } \\
\text { dermatológicas dos pacientes que fizeram uso da } \\
\text { terapêutica alternativa. }\end{array}$ & $\begin{array}{l}\text { Não descrito } \\
\text { São José do Rio Preto - SP. } \\
\text { 182/34/21 }\end{array}$ \\
\hline E16 & $\begin{array}{l}\text { MAIA, M.V. et al. Anais Brasileiros } \\
\text { de Dermatologia /2013/B1 }\end{array}$ & $\begin{array}{l}\text { Descrever efeitos adversos do esquema alternativo } \\
\text { contendo clofazimina, ofloxacina e minociclina em } \\
\text { pacientes com hanseníase multibacilar. }\end{array}$ & $\begin{array}{l}\text { Estudo prospectivo, descritivo e } \\
\text { observacional } \\
\text { Manaus - Amazonas } \\
21 \text { pacientes }\end{array}$ \\
\hline E17 & $\begin{array}{l}\text { SINGH, H. et al. Indian Journal } \\
\text { Pharmacology/ 2013/ B3 }\end{array}$ & $\begin{array}{l}\text { Descrever a enteropatia induzida por clofazimina } \\
\text { em paciente com hanseníase. }\end{array}$ & $\begin{array}{l}\text { Relato de caso/ } \\
\text { Índia } \\
\text { Homem de } 19 \text { anos. }\end{array}$ \\
\hline E18 & $\begin{array}{l}\text { GONÇALVES, } \begin{array}{c}\text { H.S. } \\
\text { Memórias do }\end{array} \text { Instituto } \text { Oswaldo } \\
\text { Cruz/ 2012/B1 }\end{array}$ & $\begin{array}{l}\text { Comparar a incidência de efeitos adversos no } \\
\text { tratamento com R-MDT vs. tratamento com U- } \\
\text { MDT }\end{array}$ & $\begin{array}{l}\text { Estudo quantitativo, randomizado } \\
\text { Fortaleza - CE } \\
818 / 60\end{array}$ \\
\hline E19 & $\begin{array}{l}\text { MARQUES, G.F. et } \text { al. } \\
\text { Hansenologia Internationalis/ 2012/ } \\
\text { B3 }\end{array}$ & Descrever um caso de síndrome da sulfona. & $\begin{array}{l}\text { Relato de caso } \\
\text { Não descrito no artigo } \\
\text { Homem de } 59 \text { anos. }\end{array}$ \\
\hline E20 & $\begin{array}{l}\text { WEIWEI,T., et al./ Leprosy } \\
\text { review/2012/B1 }\end{array}$ & $\begin{array}{l}\text { Estudar a incidência e as características clínicas da } \\
\text { Síndrome de hipersensibilidade a dapsona entre } \\
\text { pacientes com hanseníase tratados com MDT de } \\
2006 \text { a } 2009 \text { na China. }\end{array}$ & $\begin{array}{l}\text { Estudo retrospectivo } \\
\text { China } \\
6243 / 63\end{array}$ \\
\hline E21 & $\begin{array}{l}\text { GRACE, M. Indian Dermatology } \\
\text { Online Journal/ 2011/ não } \\
\text { encontrado }\end{array}$ & $\begin{array}{l}\text { Relatar um caso incomum de hipersensibilidade à } \\
\text { dapsona. }\end{array}$ & $\begin{array}{l}\text { Relato de caso } \\
\text { Não descrito no artigo } \\
\text { Homem de } 34 \text { anos }\end{array}$ \\
\hline E22 & $\begin{array}{l}\text { SINGH, H., et al. Leprosy review/ } \\
\text { 2011/ B1 }\end{array}$ & $\begin{array}{l}\text { Avaliar os efeitos adversos da poliquimioterapia } \\
\text { em pacientes com hanseníase. }\end{array}$ & $\begin{array}{l}\text { Estudo prospectivo, descritivo, } \\
\text { observacional } \\
\text { Jagdalpur } \\
176\end{array}$ \\
\hline E23 & $\begin{array}{l}\text { SILVA, I.M.C.B., et al. The } \\
\text { Brazilian Journal of Infectious } \\
\text { Diseases/ 2009/B1 }\end{array}$ & $\begin{array}{l}\text { Relatar o caso de um paciente que apresentou } \\
\text { agranulocitose e anemia hemolítica associadas a } \\
\text { PQT. }\end{array}$ & $\begin{array}{l}\text { Relato de Caso } \\
\text { João Pessoa- PB } \\
\text { Mulher de } 28 \text { anos }\end{array}$ \\
\hline E24 & $\begin{array}{l}\text { DEPS, P. et al. Leprosy } \\
\text { review/2007/B1 }\end{array}$ & Descrever os efeitos colaterais da PQT. & Retrospectivo e descritivo \\
\hline
\end{tabular}




\begin{tabular}{|c|c|c|c|}
\hline & & & $\begin{array}{l}\text { Vitória-ES } \\
194 \text { sujeitos. }\end{array}$ \\
\hline E25 & $\begin{array}{l}\text { B PANDEY, M.B.B.S., et al. } \\
\text { Tropical Doctor/ 2007/ B3 }\end{array}$ & $\begin{array}{l}\text { Descrever a mortalidade pela síndrome de } \\
\text { hipersensibilidade a dapsona. }\end{array}$ & $\begin{array}{l}\text { Estudo retrospectivo } \\
\text { Nepal } \\
\text { 1968/40 SHD/05óbitos. }\end{array}$ \\
\hline E26 & $\begin{array}{l}\text { ALVES-RODRIGUES, E.N.A et al. } \\
\text { The Brazilian Journal of Infectious } \\
\text { Diseases/ 2005/B2 }\end{array}$ & $\begin{array}{l}\text { Relatar a insuficiência renal aguda, bem como } \\
\text { outras complicações características da síndrome da } \\
\text { dapsona, durante o tratamento da hanseníase. }\end{array}$ & $\begin{array}{l}\text { Relato de Caso } \\
\text { Não descrito no artigo } \\
\text { Mulher de } 39 \text { anos }\end{array}$ \\
\hline E27 & $\begin{array}{l}\text { BUCARETCHI, F. et al.. Revista do } \\
\text { Instituto de Medicina Tropical de } \\
\text { São Paulo/2004/B2 }\end{array}$ & Descrever o relato de um caso grave a SHD. & $\begin{array}{l}\text { Relato de caso } \\
\text { Não descrito no artigo } \\
\text { Menina de } 12 \text { anos. }\end{array}$ \\
\hline E28 & $\begin{array}{l}\text { GOULART, I.M.B. et al. Revista da } \\
\text { Sociedade Brasileira de Medicina } \\
\text { Tropical/ 2002/B1 }\end{array}$ & $\begin{array}{l}\text { Determinar a magnitude dos efeitos colaterais } \\
\text { relacionados às drogas utilizadas na PQT e } \\
\text { relacionar tais efeitos como possível motivo de não } \\
\text { adesão do paciente ao tratamento. }\end{array}$ & $\begin{array}{l}\text { Estudo analítico epidemiológico } \\
\text { retrospectivo } \\
\text { Uberlândia - MG } \\
\text { Prontuário de } 187 \text { pacientes. }\end{array}$ \\
\hline E29 & $\begin{array}{l}\text { RODRIGUES, R.M.G., et al. Jornal } \\
\text { Brasileiro de Nefrologia/ 2000/ B2 }\end{array}$ & $\begin{array}{l}\text { Relatar } 02 \text { casos de IRA em pacientes após uso de } \\
\text { rifampicina. }\end{array}$ & $\begin{array}{l}\text { Relato de caso } \\
\text { Não descrito no artigo } \\
\text { Paciente } 01 \text { - homem de } 35 \text { anos } \\
\text { Paciente } 02 \text { - homem de } 53 \text { anos }\end{array}$ \\
\hline E30 & $\begin{array}{l}\text { KUMAR, R.H. et al. Indian Journal } \\
\text { Leprosy/ 1998/ B1 }\end{array}$ & $\begin{array}{l}\text { Analisar os casos de síndrome a dapsona de } 1992 \text { a } \\
1997 .\end{array}$ & $\begin{array}{l}\text { Estudo retrospectivo } \\
\text { Pondicherry - ÍndiA } \\
17 \text { sujeitos. }\end{array}$ \\
\hline E31 & $\begin{array}{l}\text { GALLO, M.E.N., et al. } \\
\text { Hansenologia Internationalis/ 1995/ } \\
\text { B3 }\end{array}$ & $\begin{array}{l}\text { Apresentar as intercorrências clínicas causadas } \\
\text { pelas drogas utilizadas nos esquemas } \\
\text { poliquimioterápicos em hanseníase. }\end{array}$ & $\begin{array}{l}\text { Estudo de coorte } \\
\text { Ambulatório Souza Araújo (ASA) } \\
\text { do Laboratório de Hanseníase da } \\
\text { FIOCRUZ } \\
980 \text { sujeitos. }\end{array}$ \\
\hline E32 & $\begin{array}{l}\text { OPROMOLLA, D.V.A.et al. } \\
\text { Hansenologia Internationalis/ 1994/ } \\
\text { B3 }\end{array}$ & Relatar um caso de síndrome da sulfona, & $\begin{array}{l}\text { Relato de Caso } \\
\text { Brasil } \\
\text { Homem de } 68 \text { anos. }\end{array}$ \\
\hline E33 & $\begin{array}{l}\text { GORDAN, P. A. et al. Hansenologia } \\
\text { Internationalis/ 1992/ B3 }\end{array}$ & $\begin{array}{l}\text { Descrever episódios de insuficiência renal aguda } \\
\text { ocorridos em sete pacientes portadores de } \\
\text { hanseníase. }\end{array}$ & $\begin{array}{l}\text { Relato de caso } \\
\text { Brasil - Londrina - PR. } \\
283 / 7\end{array}$ \\
\hline
\end{tabular}

SHD - síndrome de hipersensibilidade à dapsona; PQT - poliquimioterapia; PQT-PB - poliquimioterapia-paucibacilar; PQT-MB poliquimioterapia - multibacilar; MDT - multidrogaterapia; RMDT - multidrogaterpia regular; UMDT - multidrogaterpia uniforme; IRA infecção respiratória aguda; RAMs - reações adversas a medicamentos.

Fonte: Os autores. 
Quadro 1. Descrição dos eventos clínicos e laboratoriais relatados nos estudos frente ao uso da poliquimioterapia e as respectivas condutas adotadas em prol do controle das reações adversas.

\begin{tabular}{|c|c|c|c|c|}
\hline ID & $\begin{array}{l}\text { Droga } \\
\text { utilizada }\end{array}$ & Eventos Clínicos/Sintomas & $\begin{array}{l}\text { Eventos } \\
\text { laboratoriais/Imagem }\end{array}$ & $\begin{array}{l}\text { Condutas adotadas/Contribuições } \\
\text { esperadas/Sugestões }\end{array}$ \\
\hline E1 & $\begin{array}{l}\text { Dapsona } \\
\text { Clofazimina } \\
\text { Rifampicina }\end{array}$ & $\begin{array}{l}\text { Hiperpigmentação da pele Ictiose/Xerose } \\
\text { Metaemoglobinemia Quelite angular, } \\
\text { Erupção acneiforme, Náuseas, Dor } \\
\text { epigástrica, Dor abdominal, Hiporexia, } \\
\text { Diarreia, Vômitos, Vertigem, Insônia, } \\
\text { Cefaléia, Alterações do humor Tremores, } \\
\text { Câimbras, Fadiga e Perda de peso } \\
\text { Dapsona-alterações gastrintestinais, } \\
\text { anemia e metaemoglobinemia } \\
\text { Clofazimina-hiperpigmentação de pele e } \\
\text { a ictiose/xerose; } \\
\text { Rifampicina-hiporexia e diarreia. }\end{array}$ & $\begin{array}{l}\text { Elevação } \\
\text { Ureia/Creatinina, de } \\
\text { transaminases, Bilirrubina. } \\
\text { Eosinofilia, } \\
\text { Trombocitopenia, Anemia } \\
\text { Hemolítica e Hiperglicemia. } \\
\text { Não descrito exame de } \\
\text { imagem. }\end{array}$ & $\begin{array}{l}\text { Mudança de esquema terapêutico } \\
\text { (dapsona para clofazimina) devido efeitos } \\
\text { adversos graves (Metaemoglobinemia e } \\
\text { anemia hemolítica) } \\
\text { Profissionais da saúde capacitados para } \\
\text { diagnosticar os efeitos adversos de cada } \\
\text { droga. } \\
\text { Propor um instrumento padrão para o } \\
\text { registro das reações adversas. }\end{array}$ \\
\hline E2 & Ofloxacina & Não houve reação adversa à ofloxacina. & Não descritos. & $\begin{array}{l}\text { Não houve reação adversa a ofloxacina. } \\
\text { O uso da ofloxacina no lugar da } \\
\text { clofazimina evita a hiperpigmentação } \\
\text { cutânea causada pela droga. } \\
\text { Necessário um estudo caso-controle. } \\
\text { Uso da ofloxacina em locais não } \\
\text { endêmicos. }\end{array}$ \\
\hline E3 & $\begin{array}{l}\text { Dapsona, } \\
\text { Rifampicina } \\
\text { Clofazimina }\end{array}$ & $\begin{array}{l}\text { Dapsona-tosse seca noturna emetizante, } \\
\text { lipotímia, epigastralgia, evacuações } \\
\text { líquido-pastosas dispneia, febre e } \\
\text { sudorese noturnas, mialgia, artralgia, } \\
\text { icterícia, colúria sem acolia, rash } \\
\text { mobiliforme em tronco e abdome, } \\
\text { descamação de pele, linfonodomegalias, } \\
\text { edema de membros inferiors. SHD. }\end{array}$ & $\begin{array}{l}\text { Taxas elevadas de: } \\
\text { transaminases, bilirrubina } \\
\text { direta, e PCR. } \\
\text { Anemia normocítica e } \\
\text { normocrômica, hiponatremia, } \\
\text { hipoalbuminemia. } \\
\text { RX pulmão - pneumonia }\end{array}$ & $\begin{array}{l}\text { Ceftriaxona e metronidazol } \\
\text { hidrocortisona } \\
\text { prednisona } \\
\text { anti-histamínico } \\
\text { Rifampicina, Clofazimina e Minociclina. } \\
\text { A SHD apesar de rara, deve ser } \\
\text { diagnosticada com rapidez a fim de evitar } \\
\text { danos maiores como } \\
\text { insuficiência hepática e renal. }\end{array}$ \\
\hline E4 & $\begin{array}{l}\text { Dapsona, } \\
\text { Rifampicina } \\
\text { Ofloxacina }\end{array}$ & $\begin{array}{l}\text { Dapsona-após } 7 \text { semanas de tratamento } \\
\text { necessitou internação apresentando: febre, } \\
\text { tosse produtiva, erupção maculopapular } \\
\text { pruriginosa difusa e confluente e icterícia. } \\
\text { Diagnóstico de síndrome de } \\
\text { hipersensibilidade à dapsona (SHD). }\end{array}$ & $\begin{array}{l}\mathrm{Na} \text { internação: Anemia, } \\
\text { Elevação de transaminases, } \\
\text { fosfatase alcalina e } \\
\text { bilirrubina. } \\
\mathrm{RX} \text { de tórax - normal na } \\
\text { admissão e na internação. }\end{array}$ & 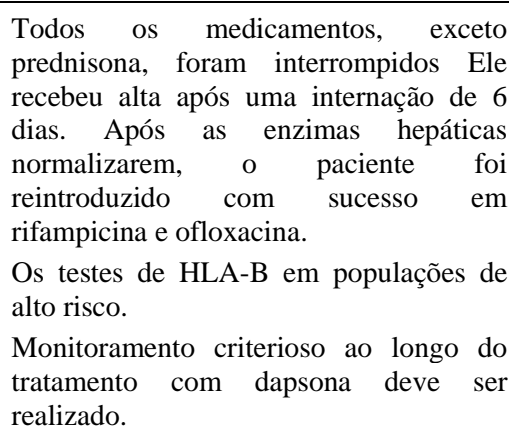 \\
\hline E5 & $\begin{array}{l}\text { Dapsona } \\
\text { Rifampicina }\end{array}$ & $\begin{array}{l}\text { Dapsona-febre, inchaço no rosto e } \\
\text { pescoço com celulite associada, disfagia, } \\
\text { dificuldade em respirar, mucosite grave, } \\
\text { trismo, sialorréia, formação de abscesso } \\
\text { profundo na região submandibular, } \\
\text { estridor. }\end{array}$ & $\begin{array}{l}\begin{array}{l}\text { Leucopenia, VHS e PCR } \\
\text { elevados }\end{array} \\
\text { Ultrasson }-\quad \text { abscessos } \\
\text { profundos com edema de pele } \\
\text { na região submandibular. }\end{array}$ & $\begin{array}{l}\text { Interrupção da dapsona. } \\
\text { Antimicrobiano de largo espectro. } \\
\text { Drenagem dos abcessos. } \\
\text { Adrenalina nebulizada e dexametasona } \\
\text { intravenosa. } \\
\text { Transfusão de hemoderivado. } \\
\text { Educação em saúde para profissionais de } \\
\text { atenção primária e pacientes atentos na } \\
\text { detecção de efeitos adversos. }\end{array}$ \\
\hline E6 & $\begin{array}{l}\text { Dapsona } \\
\text { Rifampicina }\end{array}$ & $\begin{array}{l}\text { Dapsona-Exantema maculopapular em } \\
\text { tronco, membros e mucosas } \\
\text { Dores no corpo } \\
\text { Linfadenopatia generalizada, edema } \\
\text { bilateral, tosse com expectoração, febre, } \\
\text { calafrios. } \\
\text { (SHD). }\end{array}$ & $\begin{array}{l}\text { Leucocitose } \\
\text { Elevação de transaminases } \\
\text { Histopatológico evidenciando } \\
\text { infiltrados inflamatórios. } \\
\text { Ultrasson evidenciando } \\
\text { hepatomegalia. }\end{array}$ & $\begin{array}{l}\text { prednisolona oral, paracetamol, } \\
\text { ceftriaxona, cetrizina, tramadol para dor, } \\
\text { e loção e dipropionato de beclometasona } \\
\text { para lesões na pele. } \\
\text { Acompanhado por } 6 \text { meses havendo } \\
\text { remissão da doença. } \\
\text { Profissionais da saúde deve estar ciente } \\
\text { da potencialidade fatal para o paciente } \\
\text { quando prescrito a dapsona. } \\
\text { Monitoramento criterioso ao longo do }\end{array}$ \\
\hline
\end{tabular}




\begin{tabular}{|c|c|c|c|c|}
\hline & & & & ratamento. \\
\hline E7 & $\begin{array}{l}\text { Dapsona, } \\
\text { Rifampicina } \\
\text { Clofazimina }\end{array}$ & $\begin{array}{l}\text { Dapsona - erupções cutâneas, síndrome } \\
\text { da dapsona, Anemia hemolítica, hepatite. } \\
\text { Rifampicina - síndrome semelhante à } \\
\text { gripe. } \\
\begin{array}{l}\text { Clofazimina - não houve reações } \\
\text { adversas. }\end{array}\end{array}$ & $\begin{array}{l}\text { Hemograma, função hepática } \\
\text { (TGO, TGP, GGT, fosfatase } \\
\text { alcalina) e função renal. } \\
\text { Raio-X de tórax e ultrassom } \\
\text { do abdomen. }\end{array}$ & $\begin{array}{l}\text { Os regimes alternativos foram } \\
\text { clofazimina + ofloxacina + minociclina. } \\
\text { Pesquisa de alcoolismo, hepatites virais e } \\
\text { anemia devem ser realizadas antes do } \\
\text { início da PQT de modo que qualquer } \\
\text { alteração não seja erroneamente atribuída } \\
\text { da multidroga terapia. }\end{array}$ \\
\hline E8 & $\begin{array}{l}\text { Dapsona, } \\
\text { Rifampicina } \\
\text { Clofazimina }\end{array}$ & $\begin{array}{l}\text { Dapsona }- \text { hemólise, Astenia, } \\
\text { metahemoglobinemia. } \\
\text { Rifampicina- insuficiência renal. } \\
\text { Clofazimina-diarreia crônica. }\end{array}$ & 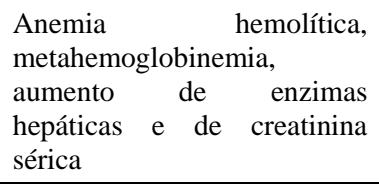 & $\begin{array}{l}\text { Estudos prospectivos que avaliem } \\
\text { indicadores de efeitos adversos e a } \\
\text { eficácia do esquema alternativo; } \\
\text { Monitorar os efeitos adversos. }\end{array}$ \\
\hline E9 & $\begin{array}{l}\text { Dapsona, } \\
\text { Rifampicina } \\
\text { Clofazimina }\end{array}$ & $\begin{array}{l}\text { Rifampicina-mal estar geral, vômitos, } \\
\text { artralgia, } \\
\text { febre, rash cutâneo e oligúria. }\end{array}$ & $\begin{array}{l}\text { Taxas elevadas de ureia, } \\
\text { creatinina e potássio. Acidose } \\
\text { metabólica, eosinofilia no } \\
\text { hemograma proteinúria, } \\
\text { cilindros leucocitários e } \\
\text { eosinofilúria. }\end{array}$ & $\begin{array}{l}\text { Suspensão da medicação e terapia renal } \\
\text { substitutiva. } \\
\text { Equipes de saúde e pacientes devem ser } \\
\text { alertados quanto à possibilidade de } \\
\text { reações adversas garantindo desta forma, } \\
\text { detecção precoce de anormalidades e } \\
\text { rápido manejo dos efeitos colaterais. }\end{array}$ \\
\hline E10 & $\begin{array}{l}\text { Dapsona, } \\
\text { Rifampicina } \\
\text { Clofazimina }\end{array}$ & $\begin{array}{l}\text { Dapsona-Anemia, transtornos hepáticos e } \\
\text { cefaléia. }\end{array}$ & Não descrito no artigo. & $\begin{array}{l}\text { vitamina } C \text {, ácido fólico e suspenção da } \\
\text { dapsona. } \\
\text { Monitoramento rotineiro da hemoglobina } \\
\text { e exames de fígado, com ênfase nos } \\
\text { primeiros } 3 \text { meses de tratamento. }\end{array}$ \\
\hline E11 & $\begin{array}{l}\text { Dapsona, } \\
\text { Rifampicina } \\
\text { Clofazimina }\end{array}$ & $\begin{array}{l}\text { Dapsona-náuseas, vômitos, epigastralgia, } \\
\text { inapetência, odinofagia, disfagia, fadiga, } \\
\text { febre, emagrecimento, prurido cutâneo, } \\
\text { icterícia, edema em membros inferiores e } \\
\text { mãos, dermatite maculo-papular em pés, } \\
\text { linfadenomegaliar submandibular } \\
\text { unilateral, mucosas hipocoradas, discreta } \\
\text { hepatomegalia } \\
\text { Sindrome da sulfona. }\end{array}$ & $\begin{array}{l}\text { Anemia hemolítica, } \\
\text { leucocitose, linfocitose, } \\
\text { eosinofilia, aumento das } \\
\text { transaminases e GGT, } \\
\text { elevação da bilirrubina total, } \\
\text { direta e indireta, aumento da } \\
\text { LDH e TAP, } \\
\text { hipoalbuminemia. }\end{array}$ & $\begin{array}{l}\text { Suspensão da PQT } \\
\text { Hemotransfusão } \\
\text { Cefalexina } \\
\text { Ceftriaxona } \\
\text { Substituição da dapsona pela ofloxacina. } \\
\text { Reconhecer precocemente o caso de } \\
\text { síndrome à dapsona. } \\
\text { Notificar os casos. }\end{array}$ \\
\hline E12 & $\begin{array}{l}\text { Dapsona, } \\
\text { Rifampicina } \\
\text { Clofazimina }\end{array}$ & $\begin{array}{l}\text { Dapsona-Icterícia, Dermatite esfoliativa, } \\
\text { Anemia hemolítica, Febre e dor de } \\
\text { cabeça, Bolhas pelo corpo, Erupções } \\
\text { cutâneas, Agranulocitose, Necrólise } \\
\text { epidérmica tóxica. } \\
04 \text { óbitos. }\end{array}$ & $\begin{array}{l}\text { Exames laboratoriais foram } \\
\text { realizados, porém não } \\
\text { descritos no artigo. } \\
\text { Não descrito exame de } \\
\text { imagem. }\end{array}$ & $\begin{array}{l}\text { Interrupção do tratamento e tratamento } \\
\text { específico para cada reação. } \\
\text { Prescrições para cada caso: azatioprina, } \\
\text { fluidos intravenosos, ofloxacina, } \\
\text { minociclina, cetirizina, Óleo de côco, } \\
\text { hidrocortisona intravenosa, Prednisolona, } \\
\text { complexo B, lactulose, Hepa-Merz } \\
\text { (desintoxicante -hepatoprotetor) } \\
\text { comprimido de Liv-52, comprimidos de } \\
\text { ferro e multivitaminas, transfusão } \\
\text { sanguinea. } \\
\text { Os médicos devem estar preparados para } \\
\text { o diagnóstico de efeitos adversos à } \\
\text { dapsona, assim como para o manejo dos } \\
\text { mesmos. } \\
\text { Adaptar o esquema preconizado nos } \\
\text { casos que comprovadamente } \\
\text { desenvolveram efeitos colaterais a uma } \\
\text { das drogas utilizadas. }\end{array}$ \\
\hline E13 & $\begin{array}{l}\text { Dapsona, } \\
\text { Rifampicina } \\
\text { Clofazimina }\end{array}$ & $\begin{array}{l}\text { Dapsona-febre, mal estar, palidez, } \\
\text { icterícia, linfonodos cervicais sensíveis, } \\
\text { erupção cutânea eritematosa } \\
\text { maculopapular generalizada com } \\
\text { escamas, dor epigástrica. }\end{array}$ & $\begin{array}{l}\text { Anemia, Função hepática e } \\
\text { renal alteradas. } \\
\text { RX de tórax e ultra- } \\
\text { sonografia de abdome e pelve } \\
\text { estavam normais. }\end{array}$ & $\begin{array}{l}\text { Interrupção do tratamento. } \\
\text { Dexametasona, cefotaxima e fluidos } \\
\text { intravenosos; anti-histamínico oral, } \\
\text { cálcio, ferro, vaselina para aplicação } \\
\text { tópica. } \\
\text { Após melhora rifampicina e a } \\
\text { clofazimina foram continuadas. } \\
\text { Conscientização para os pacientes e entre } \\
\text { os profissionais de saúde para } \\
\text { diagnóstico precoce e tratamento das } \\
\text { reações adversas à dapsona. }\end{array}$ \\
\hline
\end{tabular}




\begin{tabular}{|c|c|c|c|c|}
\hline E14 & $\begin{array}{l}\text { Dapsona, } \\
\text { Rifampicina } \\
\text { Clofazimina }\end{array}$ & $\begin{array}{l}\text { Dapsona-prostração, febre, náuseas, } \\
\text { vômitos, desidratação, palidez, icterícia, } \\
\text { edema facial e de membros inferiores, dor } \\
\text { à palpação abdominal no quadrante } \\
\text { superior direito, pele com exantema } \\
\text { generalizado que posteriormente evoluiu } \\
\text { para dermatite esfoliativa. }\end{array}$ & 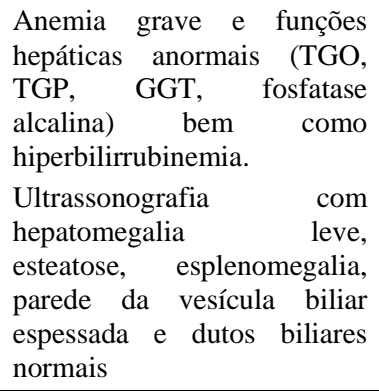 & $\begin{array}{l}\text { Suspensão da PQT e prescrito prednisona } \\
50 \text { mg / dia. } \\
\text { Posteriormente, o tratamento para } \\
\text { hanseníase foi reiniciado com ofloxacina, } \\
\text { clofazimina e rifampicina. } \\
\text { Profissionais da saúde devem estar } \\
\text { atentos aos riscos que a dapsona oferece. } \\
\text { Exames laboratoriais com frequência } \\
\text { podem prever o início da SHD. } \\
\text { Investigar HLA e MHC nos pacientes. }\end{array}$ \\
\hline E15 & $\begin{array}{l}\text { Dapsona } \\
\text { Rifampicina }\end{array}$ & $\begin{array}{l}\text { Dapsona-Anorexia, Boca amarga, } \\
\text { cefaleia, convulsão, desmaio, dispneia, } \\
\text { diarreia, emagrecimento, febre, } \\
\text { fraqueza/pernas, mal-estar geral, Dores } \\
\text { nas pernas, hipotensão, icterícia ocular, } \\
\text { náuseas, taquicardia, tonturas, urina } \\
\text { escura, vômito. } \\
\text { Rifampicina-Dor de estômago. }\end{array}$ & $\begin{array}{l}\text { Dapsona-Alteração hepática, } \\
\text { Anemia megaloblástica, } \\
\text { Anemia, Anemia crônica, } \\
\text { Anemia hemolítica, } \\
\text { Metahemaglobinemia, } \\
\text { Pancitopenia, } \\
\text { Sulfahemoglobinemia } \\
\text { Rifampicina-Alteração } \\
\text { hepática, Anemia, Hepatite } \\
\text { medicamentosa, Hepatite C, } \\
\text { Insuficiência renal aguda, } \\
\text { Necrose tubular, Síndrome } \\
\text { Pseudogripal, Transplante } \\
\text { renal. } \\
\text { Não descrito exame de } \\
\text { imagem. }\end{array}$ & $\begin{array}{l}\text { Pacientes fizeram tratamento alternativo } \\
\text { devido as reações adversas causadas pela } \\
\text { dapsona e pela rifampicina. } \\
\text { Ofloxacina no lugar da rifampicina. } \\
\text { Desafio aos profissionais da saúde } \\
\text { acompanhar os pacientes mesmo após a } \\
\text { alta. }\end{array}$ \\
\hline E16 & $\begin{array}{l}\text { Minociclina, } \\
\text { Ofloxacina } \\
\text { Clofazimina }\end{array}$ & $\begin{array}{l}\text { Prurido, Fadiga. Mialgia, Artralgia, Dor } \\
\text { de Cabeça, Insônia, Ardência nos olhos, } \\
\text { Xerose, Diminuiçãa do apetite } \\
\text { (hiporexia), Vômito, Diarréia, Dor } \\
\text { abdominal, Pigmentação da pele. }\end{array}$ & $\begin{array}{l}\text { Taxas elevadas de: uréia, } \\
\text { creatinina, transaminases. } \\
\text { Eosinofilia. } \\
\text { Não descrito exame de } \\
\text { imagem. }\end{array}$ & $\begin{array}{l}\text { Não houve interrupção do tratamento. } \\
\text { Terapia alternativa mostrou viabilidade e } \\
\text { operacionalização semelhantes } \\
\text { PQT/MB. } \\
\text { Há necessidade de acompanhamento dos } \\
\text { indivíduos e aumento do número } \\
\text { amostral para garantir a eficácia e } \\
\text { segurança em longo prazo. }\end{array}$ \\
\hline E17 & $\begin{array}{l}\text { Dapsona, } \\
\text { Rifampicina } \\
\text { Clofazimina }\end{array}$ & $\begin{array}{l}\text { Clofazimina- dor abdominal, linfonodos } \\
\text { pouco aumentados. }\end{array}$ & $\begin{array}{l}\text { Eosinofilia, hipoalbuminemia } \\
\text { e hiperglobulinemia } \\
\text { Biópsias do estômago, } \\
\text { duodeno e jejuno - histiócitos } \\
\text { com armazenamento de } \\
\text { cristal foram observados na } \\
\text { lâmina do jejuno - cristais de } \\
\text { clofazimine. }\end{array}$ & $\begin{array}{l}\text { Suspensão da PQT } \\
\text { Corticóide. } \\
\text { Prescritores devem estar cientes desse } \\
\text { efeito adverso da clofazimina para } \\
\text { fornecer tratamento adequado e evitar } \\
\text { laparotomia desnecessária. }\end{array}$ \\
\hline E18 & $\begin{array}{l}\text { Dapsona, } \\
\text { Rifampicina } \\
\text { Clofazimina }\end{array}$ & $\begin{array}{l}\text { Dapsona, Rifampicina Clofazimina } \\
\text { Dor epigástrica, dor abdominal, dor de } \\
\text { cabeça, náusea, tontura, fadiga, } \\
\text { xerodermia e pigmentação cutânea. }\end{array}$ & $\begin{array}{l}\text { Anemia, reticulocitose, } \\
\text { leucopenia, } \\
\text { elevinof̧ão de transaminases e } \\
\text { LDH. } \\
\text { Não descrito exame de } \\
\text { imagem. }\end{array}$ & $\begin{array}{l}\text { Não houve necessidade de suspender } \\
\text { nenhuma medicação. } \\
\text { Ausência de efeitos adversos graves } \\
\text { atribuídos à dapsona, rifampicina e } \\
\text { clofazimina. } \\
\text { Uso de ácido fólico como medida } \\
\text { preventiva para anemia hemolítica. }\end{array}$ \\
\hline E19 & $\begin{array}{l}\text { Dapsona, } \\
\text { Rifampicina } \\
\text { Clofazimina }\end{array}$ & $\begin{array}{l}\text { Dapsona - Febre alta, mal estado geral, } \\
\text { emagrecimento importante, eritrodermia } \\
\text { esfoliativa, linfadenomegalia generalizada } \\
\text { e } \\
\text { hepatomegalia volumosa. } \\
\text { Óbito - decorrência de choque séptico de } \\
\text { foco pulmonar. }\end{array}$ & $\begin{array}{l}\text { Anemia, leucocitose, } \\
\text { aumento de VHS, } \\
\text { transaminases e GGT; } \\
\text { hipoalbuminemia e esteatose } \\
\text { hepática leve. } \\
\text { Biópsia de pele hiperplasia } \\
\text { epitelial, infiltrado liquenóide } \\
\text { em faixa na derme papilar, } \\
\text { com intenso } \\
\text { epidermotropismo, } \\
\text { espongiose, hiperqueratose, } \\
\text { paraqueratose, apoptose de } \\
\text { queratinócitos e derrame } \\
\text { pigmentar. } \\
\text { Não descrito exame de } \\
\text { imagem. }\end{array}$ & $\begin{array}{l}\text { Substituição da dapsona por minociclina } \\
\text { e iniciado corticoterapia sistêmica. } \\
\text { Predinisona. } \\
\text { Reconhecer os principais sintomas } \\
\text { associados à síndrome da sulfona para à } \\
\text { instituição precoce do tratamento } \\
\text { adequado. O atraso no diagnóstico pode } \\
\text { aumentar a morbimortalidade. }\end{array}$ \\
\hline
\end{tabular}




\begin{tabular}{|c|c|c|c|c|}
\hline E20 & $\begin{array}{l}\text { Dapsona, } \\
\text { Rifampicina } \\
\text { Clofazimina }\end{array}$ & $\begin{array}{l}\text { Dapsona-febre, pápula, eritema, } \\
\text { escoriação, bolha, linfadenopatia, } \\
\text { icterícia, hepatoesplenomegalia, } \\
\text { desconforto gastrintestinal e neurológico, } \\
\text { miocardite tóxica. }\end{array}$ & $\begin{array}{l}\text { Alterações hematológicas, } \\
\text { hepáticas e renais. } \\
\text { Não descrito exame de } \\
\text { imagem. }\end{array}$ & $\begin{array}{l}\text { Descontinuação da dapsona, } \\
\text { glicocorticosteroide sistêmico, protetor } \\
\text { hepático, vitaminas, glicocorticosteróide } \\
\text { tópico, dexametasona, prednisona, } \\
\text { glicose, albumina, vitamina C. } \\
\text { Diagnóstico tardio da SHD pode agravar } \\
\text { o quadro do paciente podendo causar } \\
\text { óbito. }\end{array}$ \\
\hline E21 & $\begin{array}{l}\text { Dapsona, } \\
\text { Rifampicina } \\
\text { Clofazimina }\end{array}$ & $\begin{array}{l}\text { Dapsona-febre alta, erupção cutânea } \\
\text { pruriginosa, hipotenso, taquicardico, } \\
\text { erupção cutânea maculopapular } \\
\text { eritematosa e pruriginosa, palidez nas } \\
\text { extremidades } \quad \text { e } \\
\text { hepatoesplenomegalia. } \\
\text { SHD. }\end{array}$ & $\begin{array}{l}\text { Anemia. } \\
\text { VHS e TGO elevadas, } \\
\text { Ultrassonografia abdominal: } \\
\text { aumento do fígado com leve } \\
\text { aumento na textura do eco. } \\
\text { RX - de tórax estava normal. } \\
\text { Biópsia da medula óssea: } \\
\text { evidenciando supressão da } \\
\text { mesma e presença para } \\
\text { bacilos da lepra. }\end{array}$ & $\begin{array}{l}\text { Diagnóstico de DHS. } \\
\text { Dapsona interrompida. } \\
\text { Introduzido corticosteroides via oral e } \\
\text { tópica. } \\
\text { Transfusão sanguínea. } \\
\text { Após melhora continuou com } \\
\text { clofazimina e rifampicina. } \\
\text { Os médicos devem estar preparados para } \\
\text { o diagnóstico de efeitos adversos à } \\
\text { dapsona, assim como para o manejo dos } \\
\text { mesmos. }\end{array}$ \\
\hline E22 & $\begin{array}{l}\text { Dapsona, } \\
\text { Rifampicina } \\
\text { Clofazimina }\end{array}$ & 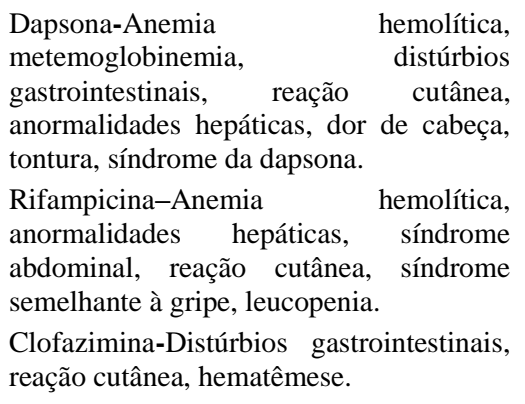 & $\begin{array}{l}\text { Anemia, Função hepática, } \\
\text { alterada. } \\
\text { Não descrito exame de } \\
\text { imagem. }\end{array}$ & $\begin{array}{l}\text { Tratamento alternativo com ofloxacina e } \\
\text { minociclina. } \\
\text { A correlação entre os efeitos adversos e } \\
\text { baixo IMC foi considerado significativo (p } \\
\text { <0,05) neste estudo. } \\
\text { Algumas reações adversas podem não ter } \\
\text { sido relatadas devido ao baixo grau de } \\
\text { instrução dos pacientes. } \\
\text { Os pacientes devem ter conhecimento das } \\
\text { reações adversas para que sejam relatadas } \\
\text { ao médicos. }\end{array}$ \\
\hline E23 & $\begin{array}{l}\text { Dapsona, } \\
\text { Rifampicina } \\
\text { Clofazimina }\end{array}$ & $\begin{array}{l}\text { dor de cabeça, dor de garganta, febre, } \\
\text { calafrios, disfagia, síncope, desidratação, } \\
\text { tonsilas hipertrofiadas e coberta por } \\
\text { placas, dor abdominal, Ausculta pulmonar } \\
\text { com murmúrio vesicular em ambos os } \\
\text { pulmões. } \\
\text { Desenvolveu granulocitose. }\end{array}$ & $\begin{array}{l}\text { Anemia, linfocitose. } \\
\text { Mielograma-hipoplasia grave } \\
\text { do componente granulocítico } \\
\text { da medula óssea e hiperplasia } \\
\text { da medula vermelha. } \\
\text { TAP e fibrinogênio - } \\
\text { alterados. } \\
\text { RX de tórax, } \\
\text { ecocardiograma, e USG } \\
\text { abdominal-normais. }\end{array}$ & $\begin{array}{l}\text { Penicilina benzatina - amigdalite. } \\
\text { Suspensão da PQT. } \\
\text { Cefepima, oxacilina, fluconazol e } \\
\text { filgrastrim. } \\
\text { Posteriormente tratamento alternativo } \\
\text { ofloxacina + clofazimina + minociclina. } \\
\text { Acompanhamento } 15 \text { dias após o início do } \\
\text { tratamento, para que os efeitos colaterais } \\
\text { adversos sejam detectados o mais } \\
\text { precocemente possível e medidas } \\
\text { adequadas sejam tomadas. }\end{array}$ \\
\hline E24 & $\begin{array}{l}\text { Dapsona, } \\
\text { Rifampicina } \\
\text { Clofazimina }\end{array}$ & $\begin{array}{l}\text { Dapsona-Anemia hemolítica, } \\
\text { Metahemoglobinemia, Leucopenia, } \\
\text { Distúrbios gastrointestinais, Distúrbios } \\
\text { psiquiátricos, Reação cutânea, Alterações } \\
\text { hepáticas, Dor de cabeça, Tontura, } \\
\text { Fraqueza muscular. } \\
\text { Rifampicina - Anemia hemolítica, } \\
\text { Alterações hepáticas, Alterações } \\
\text { gastrintestinais, deação } \\
\text { hipersensibilidade como: olhos } \\
\text { lacrimejantes, coriza, prurido, Síndrome } \\
\text { semelhante a gripe. } \\
\text { Clofazimina - Distúrbios gastrointestinais, } \\
\text { Edemas de membros inferiores. }\end{array}$ & $\begin{array}{l}\text { Exames laboratoriais foram } \\
\text { realizados, porém } \\
\text { descritos no artigo. } \\
\text { Não descrito exame de } \\
\text { imagem. }\end{array}$ & $\begin{array}{l}\text { Dapsona e Rifampicina foram } \\
\text { interrompidas. } \\
\text { Medicamentos alternativos a PQT como } \\
\text { a ofloxacina e a minociclina devem estar } \\
\text { disponíveis. }\end{array}$ \\
\hline E25 & $\begin{array}{l}\text { Dapsona, } \\
\text { Rifampicina } \\
\text { Clofazimina }\end{array}$ & $\begin{array}{l}\text { Dapsona - Febre, dermatite esfoliativa, } \\
\text { prurido, erupção papular eritematosa. } \\
5 \text { óbitos. }\end{array}$ & $\begin{array}{l}\text { Alteração de } \\
\text { bilirrabina. } \\
\text { Óbito por insuficiência } \\
\text { hepática } \\
\text { broncopneumonia. }\end{array}$ & $\begin{array}{l}\text { Prednisolona. } \\
\text { Conscientização para os pacientes e entre } \\
\text { os profissionais de saúde para } \\
\text { diagnóstico precoce e tratamento das } \\
\text { reações adversas à dapsona. }\end{array}$ \\
\hline E26 & $\begin{array}{l}\text { Dapsona } \\
\text { Rifampicina }\end{array}$ & $\begin{array}{l}\text { Dapsona - febre baixa, dor de cabeça, } \\
\text { tontura e fraqueza, tosse seca, desconforto } \\
\text { respiratório, icterícia, hepatomegalia e } \\
\text { hipotensão, edema facial, prurido, } \\
\text { erupção cutânea vesicopustular e } \\
\text { linfonodomegalia, }\end{array}$ & $\begin{array}{l}\text { Anemia, leucocitose. } \\
\text { Elevação de } \quad \text { VHS, } \\
\text { transaminases e bilirrubina. } \\
\text { hematúria e cilindros de } \\
\text { leucócitos. }\end{array}$ & $\begin{array}{l}\text { Prescrito ceftriaxona, oxacilina, } \\
\text { metilprednisolona, ciclofosfamida, } \\
\text { prednisona. } \\
\text { Hemodiálise } \\
\text { Diagnóstico de tuberculose pulmonar -, }\end{array}$ \\
\hline
\end{tabular}




\begin{tabular}{|c|c|c|c|c|}
\hline & & $\begin{array}{l}\text { esfoliativa, púrpura nas extremidades } \\
\text { inferiores, insuficiência renal aguda } \\
\text { grave, oligúria, hematúria. } \\
\text { SHD + insuficiência renal aguda. }\end{array}$ & RX de tórax normal. & $\begin{array}{l}\text { rifampicina, isoniazida e pirazinamida. } \\
\text { Ao final de seis meses, o paciente } \\
\text { continuou com rifampicina e clofazimina } \\
\text { para hanseníase } \\
\text { Dapsona foi considerada como a provável } \\
\text { causadora das reações. } \\
\text { Equipe médica deve estar ciente da } \\
\text { potencialidade fatal para o paciente } \\
\text { quando prescrito a dapsona. }\end{array}$ \\
\hline $\mathrm{E} 27$ & $\begin{array}{l}\text { Dapsona, } \\
\text { Rifampicina } \\
\text { Clofazimina }\end{array}$ & $\begin{array}{l}\text { Dapsona - Febre, mal-estar, dor de cabeça } \\
\text { e erupção cutânea, urina escura e icterícia, } \\
\text { MDT foi descontinuada. } \\
\text { Necessitou internação } 3 \text { dias depois de } \\
\text { suspender a PQT, apresentando: febre, } \\
\text { icterícia, erosões orais, conjuntivite, } \\
\text { linfadenopatia generalizada, } \\
\text { hepatoesplenomegalia, erupção cutânea } \\
\text { morbiliforme e edema de face, tornozelos } \\
\text { e mãos. } \\
\text { Piora das condiçães clínicas no hospital: } \\
\text { dermatite esfoliativa, hipotensão, edema } \\
\text { generalizado, insuficiência renal aguda, } \\
\text { insuficiência hepática, pancitopenia, } \\
\text { sangramento intestinal. } \\
\text { SHD } \\
\text { Dapsona foi considerada como a provável } \\
\text { causadora das reações. }\end{array}$ & $\begin{array}{l}\text { Anemia, } \\
\text { plaquetopenia, Elevação de } \\
\text { transaminases, } \quad \text { GGT, } \\
\text { fosfatase alcalina } \mathrm{e} \\
\text { bilirrubina. } \\
\begin{array}{l}\text { Não descrito exame de } \\
\text { imagem. }\end{array}\end{array}$ & $\begin{array}{l}\text { Administração de drogas adrenérgicas, } \\
\text { reposição de fluidos e hemoderivados, } \\
\text { antimicrobianos devido a pneumonia, } \\
\text { infecção do trato urinário e bacteremia. } \\
\text { No } 31^{\circ} \text { dia de internação, ela reiniciou o } \\
\text { tratamento com clofazimina e rifampicina } \\
\text { sem nenhum efeito adverso. } \\
\text { Dez dias após a internação houve } \\
\text { melhora do quadro com exames } \\
\text { laboratoriais normais. } \\
\text { O paciente permaneceu em tratamento } \\
\text { supervisionado. } \\
\text { Equipe médica deve estar ciente da } \\
\text { potencialidade fatal e da reação de } \\
\text { hipersensibilidade para o paciente quando } \\
\text { prescrito a dapsona. }\end{array}$ \\
\hline E28 & $\begin{array}{l}\text { Dapsona, } \\
\text { Rifampicina } \\
\text { Clofazimina }\end{array}$ & $\begin{array}{l}\text { Dapsona - Gastrite, Anemia hemolítica, } \\
\text { Cefaléia, Astenia, Dermatite esfoliativa, } \\
\text { Metahemoglobinemia, Mialgia, Dermatite } \\
\text { alérgica, Hiporexia, Insônia, Dispnéia, } \\
\text { Eritema/edema de face. } \\
\text { Rifampicina - Febre, Diarréia, cólica } \\
\text { renal, enjôo, dermatite alérgica. } \\
\text { Clofazimina - Ictiose, Ardência nos olhos, } \\
\text { Hiporexia, Náuseas, Prurido }\end{array}$ & $\begin{array}{l}\text { Exames realizados durante o } \\
\text { tratamento: Hemograma, } \\
\text { Glicemia, Urina, Função } \\
\text { hepática, Função renal, } \\
\text { Parasitológico. } \\
\text { Não descrito exame de } \\
\text { imagem. }\end{array}$ & $\begin{array}{l}\text { Dapsona: condutas de mudança no } \\
\text { tratamento, solicitações de exames e } \\
\text { prescrições de sintomáticos. } \\
\text { Rifampicina: condutas expectantes e/ ou } \\
\text { não relatadas foram predominantes. } \\
\text { Clofazimina: prescrição de sintomáticos. } \\
\text { Equipes de saúde preparadas para o } \\
\text { diagnóstico de efeitos adversos às drogas } \\
\text { da PQT, assim como para o manejo dos } \\
\text { mesmos. Protocolo de conduta que } \\
\text { priorize a introdução da PQT precedida } \\
\text { por exames laboratoriais padrão. }\end{array}$ \\
\hline E29 & $\begin{array}{l}\text { Dapsona, } \\
\text { Rifampicina } \\
\text { Clofazimina }\end{array}$ & $\begin{array}{l}\text { Rifampicina } \\
\text { 1.Tremores, artralgia, mialgia, } \\
\text { palpitações, vômitos, diarreia, eritema } \\
\text { nodoso, mal-estar, icterícia, oliguria. } \\
\text { 2.Calafrios, febre, náuseas, vômitos, } \\
\text { diarréia, oligúria, icterícia nefrite. }\end{array}$ & $\begin{array}{l}\text { 1.Anemia, plaquetopenia, } \\
\text { leucocitúria discreta, taxas } \\
\text { elevadas de: } \\
\text { bilirrubina,transaminase, } \\
\text { LDH, uréia, creatinina. } \\
\text { Ultrasson e biópsia dos rins - } \\
\text { nefrite intersticial aguda e } \\
\text { necrose tubular aguda. } \\
\text { 2.Anemia, plaquetopenia, } \\
\text { hematúria discreta, taxas } \\
\text { elevadas de: bilirrubina, } \\
\text { transaminase, LDH, } \\
\text { uréia,creatinina. Ultrasson e } \\
\text { biópsia dos rins - nefrite } \\
\text { intersticial aguda e necrose } \\
\text { tubular aguda. }\end{array}$ & $\begin{array}{l}\text { Prednisona, diálise peritoneal. } \\
\text { Transfusão de hemácias, prednisona. } \\
\text { À equipe médica deve estar atenta à } \\
\text { possibilidade de maior ocorrência de } \\
\text { lesão renal causada pela Rifampicina } \\
\text { Sintomas leves como febre, mal estar, dor } \\
\text { abdominal, vômitos ou diarreia } \\
\text { associados à ingestão da droga devem ser } \\
\text { sempre valorizados. }\end{array}$ \\
\hline E30 & Dapsona & $\begin{array}{l}\text { Dapsona-Prurido, Dermatite esfoliativa, } \\
\text { Erosões orais, Dermatite eczematosa, } \\
\text { Conjuntivite } \\
\text { Lesões bolhosas de pele, Febre, } \\
\text { linfadenomegalia, esplenomegalia, } \\
\text { hepatomegalia, ictericia. } \\
\text { Sindrome da dapsona. }\end{array}$ & $\begin{array}{l}\text { Taxas elevadas de: VHS, } \\
\text { TGO, TGP, Fosfatase } \\
\text { alcalina, bilirrubina. Anemia } \\
\text { hemolítica, eosinofilia. } \\
\text { Não descrito exame de } \\
\text { imagem. }\end{array}$ & $\begin{array}{l}\text { Interrupção do tratamento. Uso de } \\
\text { corticoide. Após melhora dapsona e a } \\
\text { rifampicina foram continuadas. } \\
\text { Monitorar os pacientes durante o uso de } \\
\text { corticoids. } \\
\text { Profissionais da saúde devem estar } \\
\text { preparados para o diagnóstico de efeitos } \\
\text { adversos à dapsona, assim como para o } \\
\text { manejo dos mesmos. }\end{array}$ \\
\hline
\end{tabular}




\begin{tabular}{|c|c|c|c|c|}
\hline E31 & $\begin{array}{l}\text { Dapsona, } \\
\text { Rifampicina } \\
\text { Clofazimina }\end{array}$ & $\begin{array}{l}\text { Síndrome da dapsona, Síndrome da } \\
\text { Rifampicina, Metahemoglobinemia, } \\
\text { Hemólise, Farmacodermia, Insuficiência } \\
\text { Renal, Hepatite. Óbito devido à lesão } \\
\text { hepática, provavelmente causada pela } \\
\text { dapsona. }\end{array}$ & $\begin{array}{l}\text { Exames laboratoriais foram } \\
\text { realizados, porém não } \\
\text { descritos no artigo. Não } \\
\text { descrito exame de imagem. }\end{array}$ & $\begin{array}{l}\text { Suspensão de todas as drogas, solicitação } \\
\text { de exames laboratoriais e internação } \\
\text { hospitalar em alguns casos. } \\
\text { Profissionais de saúde devem orientar } \\
\text { sobre possíveis efeitos colaterais. Em } \\
\text { caso de toxicidades suspender a } \\
\text { mediação. Adaptar o esquema } \\
\text { preconizado nos casos que } \\
\text { comprovadamente desenvolveram efeitos } \\
\text { colaterais a uma das drogas utilizadas. } \\
\text { Reiniciaro tratamento, adaptado ou não, } \\
\text { após a normalização do quadro clínico e } \\
\text { laboratorial. }\end{array}$ \\
\hline E32 & $\begin{array}{l}\text { Dapsona } \\
\text { Talidomida }\end{array}$ & $\begin{array}{l}\text { Dapsona-Eritema cutâneo difuso e febre, } \\
\text { dor pré-cordial súbita, sudorese intensa, } \\
\text { tosse, expectoração e dispneia, } \\
\text { adenomegalia generalizada, } \\
\text { hepatoesplenomegalia, icterícia, estertores } \\
\text { crepitantes na base pulmonar direita e } \\
\text { sibilo. } \\
\text { ÓBITO }\end{array}$ & $\begin{array}{l}\text { Leucocitose, granulações } \\
\text { tóxicas, taxas elevadas de: } \\
\text { uréia, creatinina, TGO, BD e } \\
\text { BT. } \\
\text { Quadro histopatológico } \\
\text { sugestivo de Síndrome da } \\
\text { Sulfona - necropsia. }\end{array}$ & $\begin{array}{l}\text { Na necropsia foi identificado infiltrado } \\
\text { linfocitário pleomórfico em pele, } \\
\text { mucosas e vísceras. Este quadro foi } \\
\text { interpretado como a "Síndrome da } \\
\text { Sulfona". } \\
\text { Não descritas as contribuições. }\end{array}$ \\
\hline E33 & $\begin{array}{l}\text { Dapsona, } \\
\text { Rifampicina } \\
\text { Clofazimina }\end{array}$ & $\begin{array}{l}\text { Mal-estar, mialgias, febre, dores ósseas, } \\
\text { epigastralgia, vômitos, oligúria, urina } \\
\text { escura, icterícia, diálise. } \\
\text { As } 3 \text { drogas. }\end{array}$ & $\begin{array}{l}\text { Discreta elevação dos níveis } \\
\text { de transaminases, sinais de } \\
\text { hemólise, } \\
\text { reticulocitose, anemia, } \\
\text { biópsia renal. }\end{array}$ & $\begin{array}{l}\text { Efeitos adversos atribuídos ao uso da } \\
\text { rifampicina. } \\
\text { Os pacientes deverão ser monitorados } \\
\text { com avaliação da função renal, hepática e } \\
\text { hematológica. Em casos de } \\
\text { sintomatologia exuberante, deverão ser } \\
\text { vigiados e tratados com esquemas } \\
\text { alternativos. }\end{array}$ \\
\hline
\end{tabular}

PCR - proteína C reativa; VHS - velocidade de hemossedimentação; TGO - transaminase oxalaoacética; TGP - transaminase pirúvica; GGT - gama glutamil transferase; LDH - desidrogenase láctica; TAP - tempo de atividade da protrombina; BD -bilirrubina direta; BT bilirrubina indireta; HLA - antígeno leucocitário; humano; HLA-B - antígeno leucocitário humano B; MHC - complexo de histocompatibilidade principal; IMC - índice de massa corpórea. Fonte: Os autores.

\section{Discussão}

Os principais temas exibidos pelos artigos foram os seguintes: PQT disponíveis para tratar a hanseníase e suas complicações; implicações e efeitos adversos causados pelos medicamentos; condutas para amenizar esses efeitos; capacitação para os profissionais da saúde sobre os efeitos do tratamento; relevância do paciente ser informado sobre o tratamento e seus respectivos efeitos adversos; a importância de diagnosticar e tratar a SHD com rapidez; monitoramento dos exames laboratoriais durante o tratamento; medidas preventivas para tratar possíveis complicações esperadas; notificação dos efeitos adversos e a escassez de estudos prospectivos multicêntricos que avaliem indicadores sobre os efeitos adversos e a eficácia dos esquemas terapêuticos.

O esquema de tratamento depende do perfil bacilífero e da faixa etária do paciente. Para os casos PB, até o momento, ainda utilizam RMP associada à DDS durante 6 meses, caso a DDS precise ser suspensa, utiliza-se a CFZ em conjunto à RMP, pelo mesmo período. No entanto, para os casos $\mathrm{MB}$, o tratamento de primeira linha é à associação de RMP, DDS e CFZ durante 12 meses (Castro Pante, Coelho, Carelli, Avancini \& Bianconcini Trindade, 2019).

De acordo com o Ministério da Saúde (Brasil, 2017) o tratamento em crianças é definido de acordo com o peso corporal, seguindo o mesmo esquema terapêutico instituído para os adultos. A recomendação é tomar dose diária proposta para cada fármaco, além de comparecer mensalmente na unidade de saúde para receber a dose supervisionada. Entretanto, para caso que apresentar intolerância ou contraindicação da PQT o Ministério da Saúde disponibiliza o tratamento alternativo nas unidades de referência de cada regional de saúde. Destaca ainda, que a depender do fármaco contraindicado e do perfil bacilífero, deve-se estabelecer a terapia substitutiva, introduzindo novos medicamentos, como Ofloxacino (OFX) e Minociclina (MNC) (Brasil, 2019). 
Em 2018, a Comissão Nacional de Incorporação de Tecnologias no Sistema Único de Saúde (CONITEC) (Brasil, 2018), por meio do Relatório de Recomendação N.399/2018, recomendou ao MS a ampliação do uso do medicamento CFZ para tratamento da hanseníase PB no âmbito do SUS, o que significa dizer que os pacientes acometidos pela forma clínica PB também deverão ser tratados com PQT composta por três medicamentos (RMP+ DDS + CFZ). A análise da Comissão ateve-se apenas à composição da associação medicamentosa, permanecendo, portanto, inalterado o tempo de tratamento, sendo de seis meses.

Entretanto, somente a partir de 1 de julho de 2021, a OMS atinge capacidade técnica para iniciar este novo esquema terapêutico, que passa a ser denominada "Poliquimioterapia Única (PQT-U)" tanto para os casos MB, quanto para casos PB. Estabelece que todos os pacientes diagnosticados com hanseníase PB que iniciem tratamento farmacológico a partir desta data, passem a ser tratados com PQT-U, por seis meses (Brasil, 2021).

Quanto as implicações e efeitos adversos causados pelos medicamentos, no estudo de Oliveira et al. (2019), observaram que dos 10.319 casos de hanseníase registrados entre 2010 e 2016 no sul do Brasil e na província de Missiones na Argentina, 18,9\% utilizaram esquema de tratamento substitutivo devido à intolerância medicamentosa aos fármacos da PQT.

Autores reforçam ainda, que o tempo prolongado em uso do esquema terapêutico contra a hanseníase, corroboram para os efeitos colaterais e com isso ao abandono do tratamento (Figueiredo \& Heinen, 2017; Lira, Silva \& Gonçalves, 2017; Costa, Pfrimer, Menezes, Nascimento \& Carmo Filho, 2019).

A RPM é um derivado da rifampicina B e age por bloqueio da ácido ribonucleico (RNA) polimerase ácido desoxirribonucleico (DNA) dependente, impedindo a síntese de RNA mensageiro e de proteína pelo bacilo, apresentando efeitos adversos como hepatotoxicidade, trombocitopenia e anemia hemolítica, além da Síndrome Pseudogripal, caraterizada por febre, calafrios, astenia, cefaleia, mialgia, danos renais e, por fim, choque, ocorre devido à formação de anticorpos antirifampicina, decorrente do uso intermitente do medicamento (Arbex, Varella, Siqueira \& Mello, 2010; Brasil, 2019).

No estudo de Carvalho, Ribeiro, Alves, Gomes e Sarmento (2011) relataram que a DDS é metabolizada no fígado, sendo responsável pela produção de hidroxilamina, e pelas alterações hematológicas do medicamento, como a metahemoglobina e anemia hemolítica. Karjigi et al. (2016) observaram predomínio de sintomas relacionados ao mal-estar geral, como mialgia, cefaleia e hiporexia, semelhante aos dados descritos na literatura. Lopes (2015), reforça ainda que a DDS age inibindo a conversão de ácido para-aminobenzóico, consequentemente, o ácido fólico bacteriano não é formado. Com isso há uma distribuição generalizada no organismo, com efeitos adversos maiores na pele, no fígado e nos eritrócitos e, assim, inclui efeitos como metahemoglobinemia, fotodermatite e síndrome de Stevens-Johnson.

Ademais a DDS pode causar a Síndrome da Sulfona, complicação grave, definida por um quadro eritrodérmico descamativo súbito associado à sintomatologia sistêmica; é um caso raro, grave, cuja evolução pode ser fatal. No caso da metahemoglobinemia, esta ocorrência é comum em indivíduos com deficiência de Glicose-6-Fostato Desidrogenase-G6PD, independente da dose utilizada, pois o organismo não consegue metabolizar a droga. Outros efeitos colaterais podem ocorrer, tais como, insônia e neuropatia motora periférica (Alves, Ferreira \& Ferreira, 2014; Brasil, 2019), bem como febre, mal-estar, mialgias, linfoadenomegalia generalizada, hepatomegalia e "rash" cutâneo, que se manifestam entre 2 a 5 semanas após o início do tratamento, sendo potencialmente fatal, caso não tratada adequadamente (Liu et al., 2019).

Estudo realizado por Pires et al. (2021), a mialgia (65\%) e a cefaleia (47,5\%) foram os efeitos com maior ocorrência causado pelo uso da DDS. Quanto à RPM, queixas gastrointestinais foram as mais relatadas, sendo em primeiro lugar enjoo $(32,50 \%)$, seguido de vômito (15\%), 5\% dos pacientes que utilizaram essa medicação alegaram alteração no sistema excretor. Os efeitos colaterais mais prevalentes da CFZ foram hiperpigmentação cutânea $(77,50 \%)$ e ictiose $(62,5 \%)$.

Nessa situação o Ministério da Saúde (Brasil, 2019) recomenda aos indivíduos adultos PB fazerem o uso de RMP 600mg, CFZ 300mg doses mensais e supervisionadas e CFZ 50mg dose diária autoadministrada com 6 doses em até 9 meses. 
Para os pacientes adultos MB, o uso de RMP 600mg, CFZ 300mg e OFX 400mg dose mensal supervisionada com doses diárias autoadministradas de OFX 400mg, CFZ 50mg ou MNC 100mg dose mensal supervisionada e doses diárias autoadministradas também de $100 \mathrm{mg}$, com tratamento de 12 doses e duração de até 18 meses.

Outras reações podem ocorrer com o uso da CFZ, pois tem como possíveis reações a hiperpigmentação cutânea, à ictiose e a síndrome do intestino Delgado. Quanto o uso da Ofloxacina (OFX) os efeitos adversos mais comuns estão associados aos sintomas gastrointestinais, alteração do sistema nervosa, reação de fotossensibilidade, hipersensibilidade e dermatoses (Alves et al., 2014; Brasil, 2019).

O uso da CFZ possui boa tolerabilidade e seus efeitos adversos estão associados à dose, sendo frequentemente reversíveis com a descontinuação da medicação (Brasil, 2018). As reações adversas observadas pelo uso da clofazimina foram, principalmente, pigmentação cutânea alterada (marrom-avermelhada) e ictiose, que se acentuam com o sol, deixando-a mais ressecada e sujeita a eczematizações. A pele ictiósica ocorre em quase todos os pacientes sob tratamento com esta medicação, a depender da dose e do tipo de pele. É necessário, à vista disso, alertar os pacientes em uso desse medicamento, para evitarem a exposição à luz solar e realizar uma hidratação intensiva da pele (Pires et al., 2021; Rivera et al., 2021).

Estes efeitos adversos da CFZ decorrem do depósito de cristais que podem se acumular em diversos órgãos, tais quais histiócitos da mucosa intestinal e linfonodos mesentéricos. Essa deposição pode levar à infecção intestinal e obstrução intestinal, sendo necessário, em certos casos, até mesmo indicar uma laparotomia (Brasil, 2018). Logo, pacientes com queixas abdominais, como náuseas e diarreias, devem ser acompanhados clinicamente e com possível redução ou suspensão da medicação (Lamprene, 2016).

Vale ressaltar, que a CFZ, liga-se ao DNA da micobactéria e ainda exerce uma função anti-inflamatória nas reações de eritema nodoso, é um fármaco com caráter lipofílico, com isso, pode acumular-se em tecidos adiposos e no sistema reticuloendotelial, contribuindo para o aparecimento dos efeitos adversos mais relevantes a síndrome do intestino delgado, a ictiose e a hiperpigmentação cutânea (Brasil, 2018).

E por fim, a Minociclina (MNC) tem como possíveis efeitos colaterais os sintomas gastrintestinais, cutâneos, dentários, ósseos, hematopoiéticos e no sistema nervosa central (Alves et al., 2014; Brasil, 2019).

Para Fischer (2017) os efeitos adversos graves durante o tratamento contra a hanseníase ficam somatizado, em especial, em caso de uso abusivo de álcool ou em casos que a droga é administrada intermitente, estes incluem hepatotoxicidade com testes de função hepática elevados e colestase intra-hepática. As reações imunoalérgicas são intercedidas por anticorpos IgG e IgM, estes, por sua vez, acometem plaquetas, eritrócitos e outras células, tais quais as células epiteliais tubulares renais, podendo desenvolver, respectivamente, trombocitopemia imune-mediada, anemia hemolítica e insuficiência renal aguda (Franco, 2014).

Outra recomendação frente aos efeitos adversos é para com os pacientes com hanseníase e outras comorbidades crônicas, têm desfechos clínicos piores devido à interação da PQT com outros fármacos, ainda pouco explorado nos estudos (Silva et al., 2019). Para DiPiro et al. (2014), o relato dos efeitos adversos pode estar associado a uso concomitante, por exemplo, como a metformina, hidroclorotiazida, anti-inflamatórios não esteróides e omeprazol, podendo ocorrer hemólise, efeito adverso no tratamento da hanseníase devido à DDS. Embora para Cerqueira et al. (2020) as drogas mencionadas, apesar de diferentes mecanismos de ação, produzem efeitos adversos gastrointestinais, tais como hepatoxicidade e êmese, semelhantes aos efeitos da RPM.

Um estudo recente demonstrou à importância do acompanhamento laboratorial do paciente em tratamento contra a hanseníase e o registro obrigatório nos prontuários para possível detecção precoce de algumas reações indesejáveis (Fonseca, Bertoncini, Borges, Lima \& Reis, 2020). 
Em 2015, Rocha, Lima, Stevens, Urdaneta Gutierrez e Garcia (2015) relataram os resultados de um estudo observacional retrospectivo registrados no Sistema de Informação sobre Mortalidade (SIM) no período de 2004 a 2009 em 1.463 óbitos, com a causa básica a hanseníase e sequelas da mesma. Observaram ainda, que a maior parte dos óbitos ocorreram nos primeiros 12 meses de tratamento, sobretudo nos dois primeiros meses, inferindo que os efeitos adversos da PQT possam ter relação direta com a causa para o óbito em alguns casos.

A CONITEC (Brasil, 2018) recomenda que os exames laboratoriais como hemograma, TGO, TGP e creatinina devem ser solicitados no início do tratamento, nos episódios reacionais e na suspeita de efeitos adversos a medicamentos. O retorno do paciente a unidade de saúde a cada 28 dias deve ser valorizado, pois é neste momento que ele é avaliado, recebe orientações, dúvidas são esclarecidas e em caso de reações hansênicas, efeitos adversos aos medicamentos e dano neural, são identificados pelo médico ou enfermeiro responsável pelo monitoramento clínico terapêutico afim de evitar casos graves.

No estudo realizado por Binhardi et al. (2020) descreveram que apesar da presença obrigatória de um médico especialista no acompanhamento dos casos diagnosticados de hanseníase, a pesquisa apontou que 59,8\% das unidades de saúde não cumpriam esse critério. Vale destacar que a equipe de saúde deve estar completa e estruturada de modo a oferecer assistência integral ao indivíduo com hanseníase e seus respectivos contatos domiciliares e/ou social, e, caso não disponha de médico para acompanhamento dos casos, encaminhá-los ao serviço mais próximo, onde possa ser assistido de maneira completa.

Com base nisso, o processo de capacitação profissional se faz necessário, uma vez que a educação permanente permite o encontro entre a formação e o trabalho, sendo relevante ao passo que qualifica, promove diálogos e reflexões sobre a atividade laboral a fim de transformar as práticas de saúde, bem como a assistência a população, permitindo maior efetividade e resolutividade na oferta de cuidado, estando alinhada à realidade de cada trabalhador (Almeida, Cavalcante \& Miranda, 2020; Silva et al., 2020; Maroja, Almeida Júnior \& Noronha, 2020).

Somado a isso, preparar a equipe para enfrentar esta problemática de saúde pública se faz de suma importância, haja vista que na atualidade dispomos de plataformas digitais e ensino a distância para ajudar no processo de capacitação para combate da hanseníase. $\mathrm{O}$ uso da rede mundial de computadores permite uma atualização efetiva, mais acessível e integra profissionais de diversos lugares potencializando o processo de construção de conhecimento, debate e problematização da temática em questão permitindo uma rápida difusão de informação (Obregón \& Perez, 2019).

\section{Considerações Finais}

São necessários investimentos na capacitação e educação permanente das equipes gestoras e multiprofissionais ligadas a saúde para que assim as ações repercutam de forma positiva na qualidade da assistência prestada favorecendo dessa maneira à implementação de mecanismos de vigilância e controle das reações adversas por meio de um sistema ativo e eficaz

Deve-se investir também na educação popular continuada, uma vez que o conhecimento individual é capaz de promover cuidado com a própria saúde do paciente bem como a saúde da sua família e pode gerar impacto positivo na prevenção de reações adversas.

Esta revisão é de relevância para a prática clínica, pois indica que os efeitos adversos relacionados a PQT podem ocorrer. Deve-se ter especial atenção à dapsona, pois as reações ocorrem com frequência, podendo estar associada ao óbito. Como não há exames que antecipem as reações adversas as drogas da PQT, o paciente deve ser monitorado e informado das reações que podem ocorrer e ainda orientado que ao surgir alguma reação, ele deve procurar o serviço de saúde imediatamente.

Sugere-se novos estudos afim de verificar o acompanhamento dos pacientes em tratamento com a PQT. 


\section{Referências}

Almeida, W. N. M., Cavalcante, L. M., \& Miranda, T. K. S. (2020). Educação permanente como ferramenta de integração entre agentes de saúde e de endemias. Promoção da Saúde, 33, 1-7.

Alves, E. D., Ferreira, T. L., \& Ferreira, I. N. (Orgs.). (2014). Hanseníase: avanços e desafios. NESPROM.

Arbex, M. A., Varella, M. C. L., Siqueira, H. R., \& Mello, F. A. F. (2010). Antituberculosis drugs: drug interactions, adverse effects, and use in special situations. Part 1: first-line drugs. Jornal Brasileiro de Pneumologia, 36(5), 626-640.

Binhardi, F. M. T., Nardi, S. M. T., Patine, F. S., Pedro, H. S. P., Montanha, J. O. M., Santi, M. P., ... Paschoal, V. D. (2020, Novembro). Diagnóstico da rede de atendimento laboratorial de hanseníase no Departamento Regional de Saúde XV, São José do Rio Preto, São Paulo. Epidemiologia e Serviços de Saúde [online], 29(5). Recuperado de: https://www.scielo.br/j/ress/a/LWyBVJSfjcC5mSckK6F4sbt/?lang=pt.

Brasil. (2019). Guia de vigilância em saúde (4a ed.). Ministério da Saúde.

Brasil. (2017a). Guia de vigilância em saúde: volume único (2a ed.). Ministério da Saúde. (Recurso Eletrônico). Recuperado de: http://portalarquivos.saude.gov.br/images/pdf/2017/outubro/06/Volume-Unico-2017.pdf.

Brasil. (2021). Nota Técnica $n^{\circ}$ 16/2021-CGDE/.DCCI/SVS/MS. Orientações a Estados e Municípios para a implementação da "ampliação de uso da clofazimina para o tratamento da hanseníase paucibacilar, no âmbito do Sistema Único de Saúde", conforme o determinado na Portaria SCTIE/MS N. 71, de 11 de dezembro de 2018. https://www.conass.org.br/wp-content/uploads/2021/07/SEI_MS-0020845770-Nota-Te\%CC\%81cnica-16.pdf.

Brasil. (2018). Relatório de Recomendação CONITEC: ampliar o uso da clofazimina para hanseníase paucibacilar (n. 399). Ministério da Saúde.

Brasil. (2020, Julho). Situação epidemiológica da hanseníase em 2019: um olhar para os principais indicadores do programa. Boletim Epidemiológico, 51(28), $37-45$.

Carvalho, C., Ribeiro, N., Alves, C., Gomes, H., \& Sarmento, A. (2011). Methemoglobinemia: case report and review. Arquivos de Medicina, 25(3), 100-106.

Castro Pante, C., Coelho, S. C., Carelli, L., Avancini, J., \& Bianconcini Trindade, M. A. (2019, Enero/Abril). Reacciones adversas graves a la multiterapia para la lepra registradas en servicios especializados, entre 2012 y 2017, en Brasil. Fontilles. Revista de Leprología, 31(1), 27-34.

Cerqueira, S. R. P. S., Santos, L. S., Morelo, E. F., Santos Júnior, A. C. M., Sousa, C. A. F., Gonçalves, R. T., ... Gomes, C. M. (2020). The interference of polypharmacy and the importance of clinical pharmacy advice in the treatment of leprosy: a case-control study. Revista da Sociedade Brasileira de Medicina Tropical, 53.

Costa, A. K. A. N., Pfrimer, I. A. H., Menezes, A. M. F., Nascimento, L. B., \& Carmo Filho, J. R. (2019, Fevereiro). Aspectos clínicos e epidemiológicos da hanseníase. Revista de Enfermagem UFPE on line, 13(2), 353-362.

Deps, P. D., Nasser, S., Guerra, P., Simon, M., Birshner, R. C., \& Rodrigues, L. C. (2007). Adverse effects from multi-drug therapy in leprosy: a Brazilian study. Leprosy Review, 78(3), 216-222.

DiPiro, J. T., Yee, G. C., Posey, M., Haines, S. T., Nolin, T. D., \& Ellingrod, V. (2014). Pharmacotherapy: a pathophysiologic approach (9th ed.). McGrawHill.

Fabbri, S., Silva, C., Hernandes, E., Octaviano, F., Di Thommazo, A., \& Belgamo, A. Improvements in the StArt tool to better support the systematic review process. (2016, June). Proceedings of the $20 t^{h}$ International Conference on Evaluation and Assessment in Software Engineering, University of Limerick.

Figueiredo, P. V., \& Heinen, R. C. (2017). Poliquimioterapia no tratamento da hanseníase. Revista Saúde Física \& Mental, 5(2), 59-69.

Fischer, M. (2017). Leprosy an overview of clinical features, diagnosis, and treatment. Journal of the German Society of Dermatology, 5(8), 801-827.

Fonseca, H. G., Bertoncini, P. M. R. P., Borges, J. A. M., Lima, T. M., \& Reis, P. A. M. (2020, June). Systematization of nursing care to an elderly with leprosy. Brazilian Journal of Development, 6(6), 40843-40853.

Franco, L. A. (2014). Reações adversas à poliquimiterapia em hanseníase [Dissertação de Mestrado, Universidade Federal de Sergipe, São Cristóvão].

Guragain, S., Upadhayay, N., \& Bhattarai, B. M. (017). Adverse reactions in leprosy patients who underwent dapsone multidrug therapy: a retrospective study. Clinical Pharmacology: Advances and Applications, 9, 73-78.

Karjigi, S., Murthy, S. C., Kallappa, H., Kusuma, M. R., Aruna, B., \& Reddy, Y. N. (2016). Dapsone: an update. Indian Journal of Leprosy, 87(4), 233-239.

Lamprene: cápsulas. (2016). East Hanover, New Jersey: Novartis Pharmaceuticals Corporation. Bula de remédio.

Liberati, A., Altman, D. G., Tetzlaff, J., Mulrow, C., Gøtzsche, P. C., Ioannidis, J. P. A., Moher, D. (2009). The PRISMA statement for reporting systematic reviews and meta-analyses of studies that evaluate health care interventions: explanation and elaboration. Journal of Clinical Epidemiology, 62(10), e1-e34.

Lira, R. M. N., Silva, M. V. S., \& Gonçalves, G. B. (2017, Outubro/Dezembro). Fatores relacionados ao abandono ou interrupção do tratamento da hanseníase: uma revisão integrativa daliteratura. Revista de Enfermagem da UFPI, 6(4), 53-58.

Liu, H., Wang, Z., Bao, F., Wang, C., Sun, L., Zhang, H., Liu, Q. (2019, June). Evaluation of prospective HLA-B*13:01 screening to prevent dapsone hypersensitivity syndrome in patients with leprosy. JAMA Dermatology, 155(6), 666-672. 
Lopes, M. Q. P. (2015). Avaliação dos fenótipos de aceitação e hidroxilação predominantes nas populações de 5 macrorregiões do Brasil baseada no genomapossível influência da farmacogenética na conduta terapêutica da hanseníase [Tese de Doutorado, Fundação Oswaldo Cruz, Instituto Oswaldo Cruz, Rio de Janeiro].

Margarido, L. C., \& Rivitti, E. (2015). Hanseníase. In R. Veronesi (Org.). Tratado de infectologia (5a ed., pp 939-972). São Paulo: Atheneu.

Maroja, M. C. S., Almeida Júnior, J. J., \& Noronha, C. A. (2020). Os desafios da formação problematizadora para profissionais de saúde em um programa de residência multiprofissional. Interface - Comunicação, Saúde, Educação, 24, e180616.

Moher, D. A. L., Tetzlaff, J., \& Altman, D. (2009). Preferred reporting items for systematic reviews and meta-analyses: the PRISMA statement. Annals of Internal Medicine, 4(51), 264-270.

Obregón, P. L., \& Perez, C. C. (2019). Utilização de recursos de tele-educação em um hospital universitário da região oeste do Paraná. Saúde em Rede, 5(2), 89-102.

Oliveira, K. S., Arcoverde, M. A. M., Deschutter, E. J., Silva, A. J., Zilly, A., \& Sobrinho, R. A. S. (2019). Hanseníase em países fronteiriços na américa do Sul: um estudo ecológico. Cogitare Enfermagem, 24, e64917.

Pandey, B., Shrestha, K., Lewis, J., Hawksworth, R. A., \& Walker, S. L. (2007). Mortality due to dapsone hypersensitivity syndrome complicating multi-drug therapy for leprosy in Nepal. Tropical Doctor, 37(3), 162-163.

Pires, C. A. A., Santos, M. A, L., Biasi, B. H., Moreira, A. G., Coimbra, A. C., Ferreira, M. C., ... Carneiro, F. R. O. (2021). Análise da ocorrência de reações adversas à poliquimioterapia no tratamento para hanseníase. Revista Eletrônica Acervo Saúde, 13(2), e6233-e6233.

Rocha, M. C. N., Lima, R. B., Stevens, A., Urdaneta Gutierrez, M. M., \& Garcia, L. P. (2015, Abril). Óbitos registrados com causa básica hanseníase no Brasil: uso do relacionamento de bases de dados para melhoria da informação. Ciência \& Saúde Coletiva, 20(4), 1017-1026.

Rivera, J. G. B., Medeiros, G. K. C. Q., da Silva, V. M., Magno, D. S. M., Holanda, M. R., \& Silva, Z. G. (2021). Efeitos tóxicos do tratamento farmacológico de primeira linha para hanseníase Toxic effects of first-line pharmacological treatment for leprosy. Brazilian Journal of Health Review, 4(3), $11269-11282$.

Santos, C. M. C., Pimenta, C. A. M., \& Nobre, M. R. C. (2007, Maio/Junho). A estratégia PICO para a construção da pergunta de pesquisa e busca de evidências. Revista Latino-Americana de Enfermagem, 15(3).

Silva, D. L. G., Silva, E. G., Batista, W. A., Khouri, A. G., Oliveira, R. F. R., Silveira, A. A., ... Souza, A. P. S. (2019, Agosto/Dezembro). Novas perspectivas do diagnóstico e tratamento da hanseníase. Revista Referências em Saúde da Faculdade Estácio de Sá de Goiás, 2(3), 75-81.

Silva, T. P. S., Sousa, F. O. S., Leite, G. A., Pereira, M. E. M., Gomes, M. C. T., Rodrigues, M., ... Nascimento, C. M. B. (2020). Tele-education applied to human communication health to cope with triple epidemics in the state of Pernambuco, Brazil: an experience report. Revista Cefac, 22(3), 10-19.

Singh, H., Azad, K., \& Kaur, K. (2011, March/April). Clofazimine-induced enteropathy in a patient of leprosy. Indian Journal of Pharmacology, 45(2), 197198.

Soucre, N., Martínez, I., Crespo, L., Guevara, J. R., \& Oliver, M. (2018). Reacciones adversas al tratamiento de la enfermedad de Hansen con poliquimioterapia. Estudio clínico y epidemiológico. Instituto de Biomedicina, Caracas. Periodo 2014-2015. Dermatología Venezolana, 56(1), $49-54$.

Wang, N., Parimi, L., Liu, H., \& Zhang, F. (2017). A review on dapsone hypersensitivity syndrome among Chinese patients with an emphasis on preventing adverse drug reactions with genetic testing. The American Journal of Tropical Medicine and Hygiene, 96(5), 1014-1018.

Whittemore, R., \& Knafl, K. (2005). Uma revisão integrativa: uma metodologia atualizada. Journal of Advanced Nursing, 52(5), 546-553. 